\title{
MULTI-OBJECTIVE TWO-STAGE STOCHASTIC PROGRAMMING FOR ADAPTIVE INTERDISCIPLINARY PAIN MANAGEMENT WITH PIECE-WISE LINEAR NETWORK TRANSITION MODELS
}

\author{
By \\ GAZI MD DAUD IQBAL
}

Presented to the Faculty of the Graduate School of The University of Texas at Arlington in Partial Fulfillment of the Requirements for the Degree of DOCTOR OF PHILOSOPHY

UNIVERSITY OF TEXAS AT ARLINGTON

July 2017 
To my family, friends and teachers 


\section{Acknowledgments}

I would like to take this opportunity to thank all the people who have helped me directly or indirectly to complete my $\mathrm{PhD}$.

First, I want to express my deepest thanks to my dissertation supervisor Dr. Jay M. Rosenberger. In the beginning of my $\mathrm{PhD}$, I didn't know anything about optimization, mathematical modeling, and programming. I have taken four classes with Dr. Jay, and doing research under his supervision since the beginning of my $\mathrm{PhD}$. I have learned a lot from him both in classes and in our research meetings. I doubt I would have been able to finish my PhD if Dr. Jay hadn't shared his mathematical modeling and programming knowledge with me. I was so lucky to have Dr. Jay as my supervisor. I want to thank him for his guidance, patience, and encouragement.

I would also like to thank Dr.Victoria Chen for her continuous support. She was always helpful to me whenever I needed something. I want to thank her for providing me with constructive criticism, which helped me to do better in my research. I want to thank Dr. Robert J. Gatchel for his enormous input in this research. He was always available when I needed any clarifications about pain management. I want to thank him for his additional domain expertise in pain management with this research. I would also like to thank Dr. Aera LeBoulluec for her support. I would also like to thank the Eugenne McDermott Center for pain management at UT Southwestern Medical Center for providing data.

I would like to thank all my COSMOS lab mates I worked with and I learned from. I would like to mention few names among the previous COSMOS students i.e. Dr. Piyush Kumar, Dr. John Dickson, Dr. Alireza Noroziroshan, Dr. Antonio Alanis, and Dr. Na Wang. I have learned a lot from them. They were always supportive and helpful.

Finally, I would like to thank my parents and siblings, who were always supportive of me. Their support helped me to finish my study in the US as an international student. I want to express my appreciation to my brother-in-law, Showkat Akber, for his endless support and love. 


\begin{abstract}
MULTI-OBJECTIVE TWO-STAGE STOCHASTIC PROGRAMMING FOR ADAPTIVE INTERDISCIPLINARY PAIN MANAGEMENT WITH PLN TRANSITION MODELS
\end{abstract}

\author{
Gazi Md Daud Iqbal
}

The University of Texas at Arlington, 2017

Supervising Professor: Jay M. Rosenberger

Pain is the most common symptom when a patient visits a physician. People experience pain throughout their lifetime at different degrees. If short term pain is not treated properly, then it can become long term pain, which is also known as chronic pain. The Eugene McDermott Center for pain management at UT Southwestern Medical Center conducts a two-stage pain management program for chronic pain. This research uses a two-stage stochastic programming approach to optimize personal adaptive treatment strategies for pain management. The goal is to generate adaptive treatment strategies using statistics based optimization approaches that can be used by physicians to prescribe treatment to the patients. Transition models predict how a patient with certain characteristics will react to treatments. This research uses Piecewise Linear Networks (PLN) to represent transition models. A mixed integer linear program is developed to integrate those PLN transition models into an optimization problem.

In this research we have considered five pain outcomes. To balance between different pain outcomes in the objective, we developed a survey for physicians, which is actually a pairwise comparison of different levels of different pain outcomes. Survey inputs are subjective and vary from physician to physician. In other words, inputs from multiple surveys are not entirely consistent. To get consistent weights for different levels of different pain outcomes in the two-stage stochastic program, we developed a convex quadratic programming model.

To speed up the solution process, we developed additional constraints based upon 3-way treatment interactions. These 3-way treatment interaction constraints are totally consistent with twoway treatment interaction constraints. These additional constraints do not eliminate real integer solutions, but they may eliminate fractional solutions in the branch-and-bound algorithm. We then solved the original MILP with these additional logical style constraints to see the improvement in MILP. 


\section{Contents}

1 Introduction $\quad 4$

2 Literature Review $\quad 8$

2.1 Background of Pain Management Research _ . . . . . . . . . . . . . 8

2.2 Multi-Objective Health Care Optimization . . . . . . . . . . . . . . . . . 9

2.3 Piecewise Linear Network Model _ . . . . . . . . . . . . . . . . . . . . 10

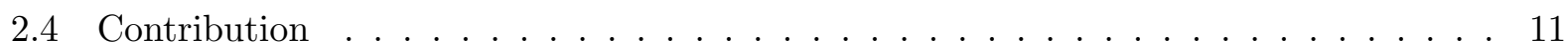

3 Mathematical Model $\quad 12$

3.1 Stochastic Programming Formulation . . . . . . . . . . . . . . . . . . . 12

3.2 Convex Quadratic Programming Formulation to get Weights . . . . . . . . . . 13

3.3 Mixed Integer Linear Programming for Piecewise Linear Network Models . . . . . . 15

3.4 Three-way Treatment Interaction Constraints . . . . . . . . . . . . . . . . . . 17

3.4.1 Linearization of Continuous Treatment Interaction Constraints . . . . . . . . 21

3.4.2 Linearization of Integer Treatment Interaction Constraints . . . . . . . . . . . 24

4 Solution Approach $\quad 27$

4.1 Case Study . . . . . . . . . . . . . . . . . . . . . . 27

4.2 Weights from Convex Quadratic Programming . . . . . . . . . . . . . 28

4.3 Treatment Cost Coefficient . . . . . . . . . . . . . . . . . . 28

4.4 Sample size determination . . . . . . . . . . . . . . . . . . . 29

4.5 Treatment Analysis . . . . . . . . . . . . . . . . . . . 31

4.5.1 First Stage Treatment Usage in different Scenario . . . . . . . . . . . . . . . 31

4.5.2 First Stage Treatment Comparison _ . . . . . . . . . . . . . . . 32

4.5.3 Second Stage Treatment Usage in different Scenario . . . . . . . . . . . . . . 32

4.5.4 Second-Stage Treatment Comparison . . . . . . . . . . . . . . . . . . . 32

4.6 Final Pain Outcome Comparison . . . . . . . . . . . . . . . . . . . 33

4.7 Results from Additional 3-way Treatment Interaction Constraints . . . . . . . . . . . 34

5 Conclusion and Future Work $\quad 36$ 


\section{List of Tables}

3.1 Description of Variables . . . . . . . . . . . . . . . . 18

3.2 Two-way Treatment Interaction Table . . . . . . . . . . . . . . . . . . 21

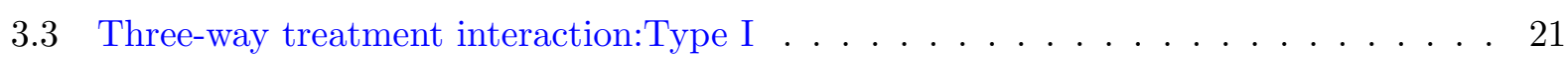

3.4 Three-way treatment interaction:Type II . . . . . . . . . . . . . . . . . . 21

3.5 Three-way treatment interaction:Type III . . . . . . . . . . . . . . . . . 22

3.6 Questionnaire for OSW vs. PDA . . . . . . . . . . . . . . . . 25

3.7 Questionnaire for OSW vs. sf36pcs . . . . . . . . . . . . . . 25

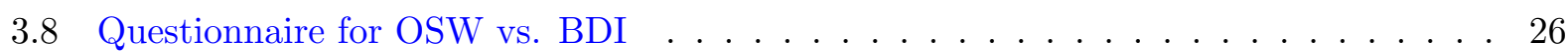

3.9 Questionnaire for OSW vs. sf36mes . . . . . . . . . . . . . 26

4.1 Determination of Treatment Coefficient . . . . . . . . . . . . . 28

4.2 Pain Outcome Comparison _. . . . . . . . . . . . . . . . . . . 34

4.3 Three-way treatment interaction Results: Continuous . . . . . . . . . . . . . . . 34

4.4 Three-way treatment interaction Results: Integer . . . . . . . . . . . . . . . . . 35 


\section{List of Figures}

1.1 The Three Biopsychosocial Domains of Pain . . . . . . . . . . . . . . 5

1.2 Two-stage Interdisciplinary Pain Management Program $[12] \ldots \ldots$. . . . . . . 5

1.3 Different Pain Outcomes and their Labels . . . . . . . . . . . . . . . . . . . 6

2.1 Structure of Piecewise Linear Network $[23] \ldots \ldots \ldots \ldots$. . . . . . . . 10

3.1 Three-way treatment interaction: Continuous . . . . . . . . . . . . . . 22

3.2 Three-way treatment interaction: Integer $\ldots \ldots \ldots \ldots \ldots \ldots$

4.1 Penalty weights for OSW, PDA, BDI, SF36-pcs, and SF36-mcs . . . . . . . . . . . 29

4.2 Average CPU time in different scenarios in Training and Testing data . . . . . . . . . . . 30

4.3 Average Objectives in different scenarios f . . . . . . . . . . . . . . . 30

4.4 First Stage Treatment Analysis _. . . . . . . . . . . . . . . . . . 31

4.5 Second Stage Treatment Analysis . . . . . . . . . . . . . . . 33 


\section{Chapter 1}

\section{Introduction}

Everyone throughout their lifetime will experience pain at various times and to varying degrees. Indeed, pain is the most common reason for people to seek medical assistance [1]. "Pain is always something that hurts" [2]. When a patient visits a physician, the most common symptom is pain, which is highly subjective, and the perception of pain involves various brain-peripheral feedback mechanisms.

The pain experience involves three interactive domains: physiological, psychological, and social (i.e., the biopsychosocial model) as shown in Figure 1.1. Treatment of pain involves dealing with the complex biopsychosocial changes of patients. For example, pain and depression are related to each other; people who have depression report more pain than non-depressed individuals. Therefore, many biopsychosocial factors are involved for treatment when a patient complaining with pain visits a physician. Some of these factors determine the causes of pain, duration, pain intensity, etc. Pain can be short-term or long-term, and its type and level can differ from patient to patient. Short-term pain that lasts a maximum 6 months is also known as acute pain. If short-term pain is not appropriately treated, then it can persist and become chronic, which is also known as chronic pain. Research shows that two-thirds of elderly people suffer from at least two chronic conditions [3]. Acute pain is fast, intense, and localized, while chronic pain is slow, diffuse, and prolonged [4]. People with chronic pain require more treatment than patients with acute pain. Chronic pain reduces a person's quality-of-life, and working capability as well [5]. Many patients are somewhat afraid to report pain because they fear: having a surgery; long-term treatment; losing social independence; etc. In some cases, they are not able to verbalize their pain condition to physicians. Surgery, cancer, fractures, etc. are directly responsible for causing acute pain. Arthritis, cancer, diabetic neuropathy, and back pain syndrome are responsible for chronic pain [6]. Chronic pain is related to medical and physical conditions as well. In most instances, the best solution for pain management is when drug and non-drug therapies can be used together in a coordinated manner.

A total of 65 million people have low back pain in the United States [7]. In the next 30 years, the number of older adults in the United States is expected to double [8]. Two-thirds of older adults are suffering from back pain. For example, Cooner and Amorosi conducted a telephone pool in New York City, which showed that almost 50\% of elderly people suffered from chronic pain and 


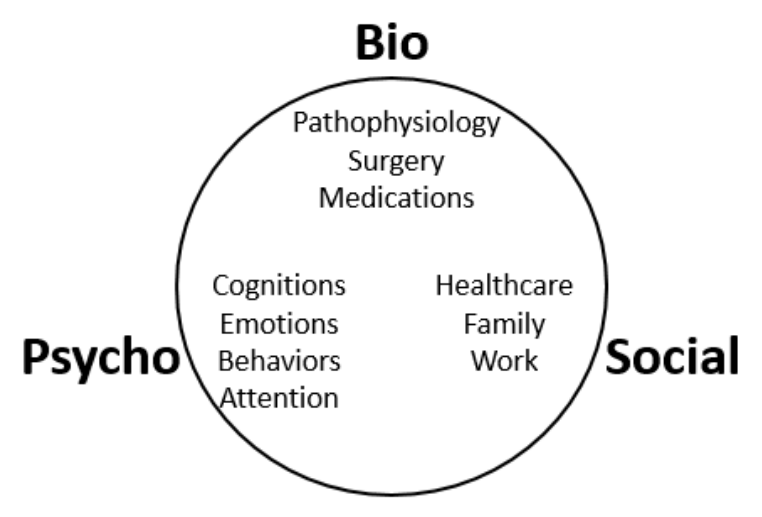

Figure 1.1: The Three Biopsychosocial Domains of Pain

had taken pain medications. It should also be noted that 51.4 million inpatient surgical procedures were performed in 2010 [9], and more than 25 million outpatient surgeries are performed each year in 5300 certified surgery centers in the U.S. [10]. Many of the surgeries are conducted on older adults. Among these, $80-85 \%$ are experiencing some health problems that contribute to the pain. In order to get rid of this unwanted pain, $45 \%$ of older adults visit at least three physicians [11].

The Eugene McDermott Center for Pain Management at UT Southwestern Medical Center administers an interdisciplinary two-stage pain management program for chronic pain. Figure 1.2 demonstrates that, at the beginning of the program, a patient goes through a preliminary treatment evaluation, which includes review of past medical records, the patient's demographic information, and biopsychosocial examinations.

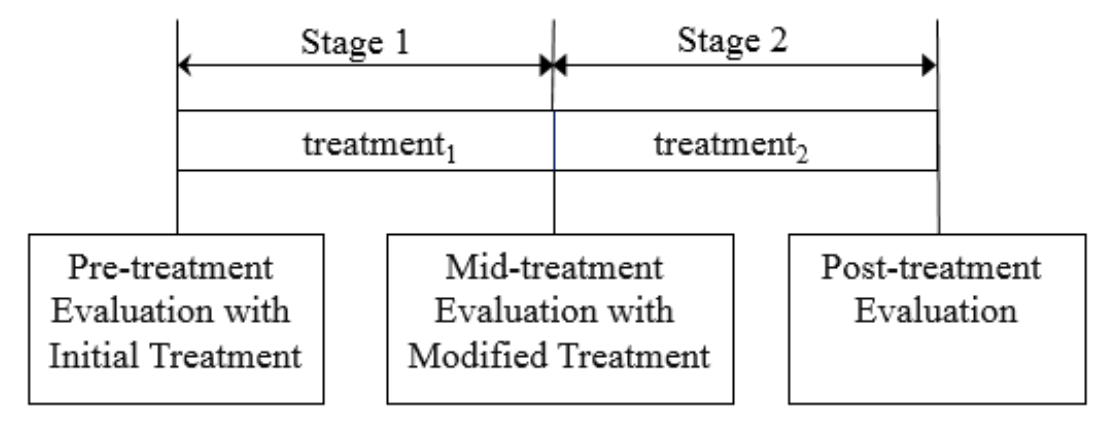

Figure 1.2: Two-stage Interdisciplinary Pain Management Program [12]

Based on these evaluations, physicians prescribe a treatment plan for the patient, which is the beginning of Stage 1. After a certain period of time, patients visit the Center again and go through another evaluation, which is called the mid-treatment evaluation. Physicians then review the pain outcomes of the evaluation and prescribe a new set of treatments to the patients if needed, which is the end of Stage 1 and beginning of Stage 2. The post treatment evaluation, where final pain outcomes are measured, ends the two-stage pain management program. Patients go through another evaluation program after one year of this two stage pain management program. In this 
research, we will not consider this last evaluation. It should also be noted, that time duration between each stage varies from patient to patient. For some patients it is 6 months, and for some it is 1 year.

A number of pain outcome measures are used to identify the intensity of pain. These include : the Beck Depression Inventory (BDI); Dallas Pain Questionnaire (DPQ); Oswestry Pain Disability Index (OSW); Pain Drawing Analogue (PDA); Multidimensional Pain Inventory (mpi); 36-item Short Form Survey Physical Component Score (SF36pcs); and 36-item Short Form Survey Mental Component Score (SF36mcs). In this present study, we consider the OSW, PDA, BDI, SF36pcs, and SF36mcs pain outcome measures.

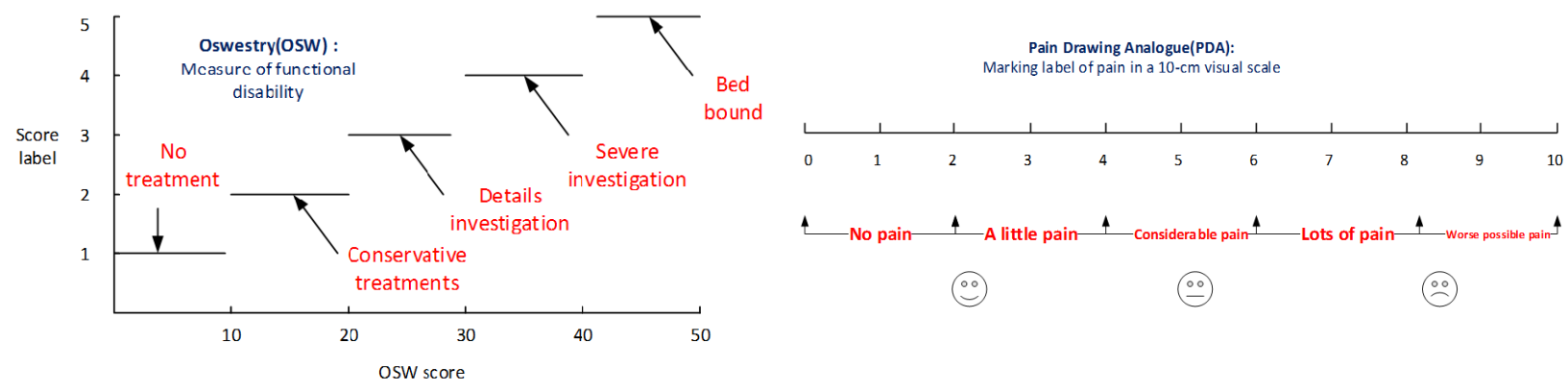

(a) OSW label

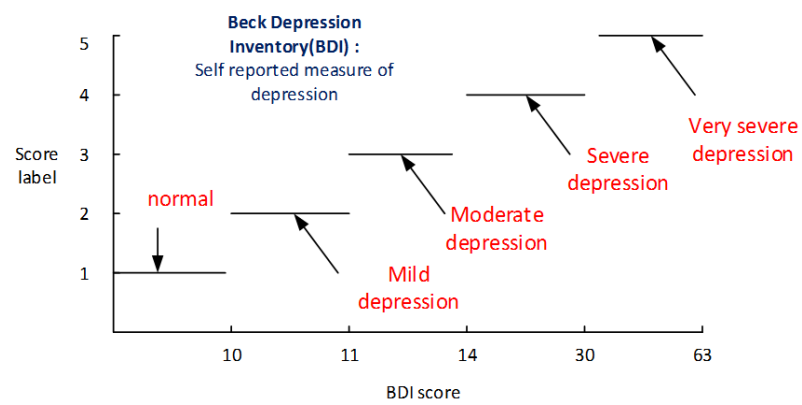

(c) BDI label (b) PDA label

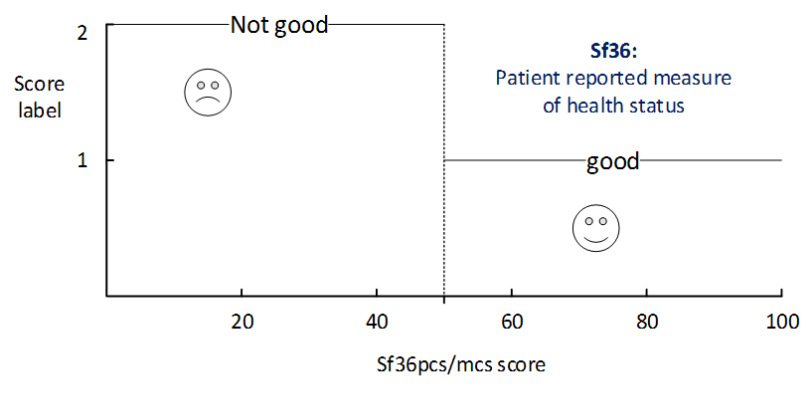

(d) SF36pcs/mcs label

Figure 1.3: Different Pain Outcomes and their Labels

The OSW is a measurement of perceived functional disability that happens because of pain. It is most widely used for assessing the disability level of back pain. It has different score levels. The OSW has 10 sections, and each section has score range of $0-5$, with a maximum possible score of 50 (1.3a). A raw score of 0-10 reflects minimal disability (No Treatment Necessary); 11-20 signifies mild disability (Conservative treatment recommended); 21-30 signifies severe disability (Detailed Investigation required); 31-40 signifies Crippling Disability (Severe Intervention required); and 4150 signifies Bed bound [13]. For the PDA scale, patients are asked to mark their level of pain on a 10-cm visual analogue scale as show in Figure 1.3b. This PDA outcome which ranges from 0-10, and was classified in to five levels: PDA value 0-2 means no pain; 3-4 means a little pain; 5-6 means considerable pain; 7-8 means a lot of pain; and 9-10 means worse possible pain. The BDI is a 
self-reported measure of symptoms of depression. It has a total of 21 questions, and each question has score range of 0-3, with a possible maximum score of 63 (1.3c). Score 0-10 signifies normal; 11 signifies mild depression; 12-14 signifies moderate depression; 15-30 signifies severe depression; and 31-63 signifies severe depression. SF-36 pcs/mcs score is a patient-reported health status measure. Its score ranges from 0-100; a mean score of 50-100 is assumed to be indicative of good for health $(1.3 \mathrm{~d})$.

In the next section, we present a literature review of the research done for pain management, multi-objective health care optimization, and piece-wise linear network models. Then, we discuss the mathematical models that we have used to generate adaptive treatment strategies for patients, which include - stochastic programming formulation, convex quadratic formulation to get weights, mixed integer linear programming formulation for piece-wise linear network models, and linearization of three-way treatment interaction constraints. Next, we present the computational results based on previous models. Then, we discuss the conclusions and future works. 


\section{Chapter 2}

\section{Literature Review}

This chapter provides the literature review on background of pain management research and optimization modeling for health care services. Section 2.1 discusses previous researches that has been done for managing pain. Section 2.2 focuses on multi-objective approaches used for health care optimization. Section 2.3 discuses peice-wise linear network modeling approaches to generate state transition models.

\subsection{Background of Pain Management Research}

Wang [14] developed a two-stage stochastic programming model for adaptive pain management, where transition models that are used as constraints are non-convex and quadratic. These nonconvex quadratic models are then refitted using a piecewise linear approximation. Prediction accuracy of the refit model was higher than the original model, and at the same time, the refit models maintain all of the original model's assumptions. By using these mathematical models, they found an optimal adaptive treatment strategies for patients. The treatment policy generated by approximated Mixed Integer Linear Program (MILP) is better than the original non-convex MINLP model in terms of solution quality and time required for optimization. They showed that policy generated by the refitted MILP model is 5.7 times more likely to achieve normal pain level compared to the observational dataset. The objective value achieved by the MILP in 6 minutes is less than the objective value from the Mixed Integer Non-Linear Program (MINLP), which takes 15 minutes. Lin [12] employed a stochastic dynamic programming approach, which considers the expected final outcomes when determining treatment. They employed approximate dynamic programming (ADP) solution methods where transition models are constructed empirically, and the future value function is approximated using state space discretization based on a Latin hypercube design. By using ADP, they were able to identify a recommended treatment regime very fast, which minimizes pain while penalizing excessive costs. LeBoulluec [15] developed a process based on the Inverse Probability of Treatment Weighted method to address the endogeneity that handles the complexity of the data set. Endogeneity happens when an independent variable is correlated with error terms. In pain management data, endogeneity occurs because of correlation of state and decision variables. Treat- 
ment affects will be biased with the presence of endogeneity. Unbiased estimatation of the casual effect of treatment on the outcome cannot be achieved because of endogeneity. They overcome this endogeneity issue using logistic regression. Treatments can be independent or correlated. Two methodologies were developed to overcome endogeneity that happened because of independent and correlated treatments.

\subsection{Multi-Objective Health Care Optimization}

Generally, preventive health care programs are used to identify serious medical conditions in early stage, which can save money and lives. Wei et al. [16] developed a bi-objective model that uses interchange algorithms to find optimal locations for preventive health care facilities. The two objectives of their optimization model were efficiency of the facility locations and coverage of patients. Optimal preventive health care facility locations always maximize participation. Accessibility of health care service is the key player in participation. Wei et al. [16] developed a new accessibility measurement. In traditional approaches, accessibility is measured based on distance, while Wei et al. [16] used a combination of distance, two-step floating catchment area method, and a Huff-based model as an accessibility measurement. Research has been done to develop a decision support tool that can be used to identify the optimal required workforce in hospitals. Ahmed and Alkhamis [17] developed a framework, which used simulation and optimization. The objective function was to maximize patient throughput and reduce patient waiting time. A deterministic budget constraint and stochastic patient waiting time was used as a constraint. They considered five decision aspects, which are required number of treatment room nurses, emergency room nurses, receptionists, doctors, and lab technicians. A decision support tool was applied to a hospital in Kuwait. It shows that a patient's waiting time can be reduced to $40 \%$, and a $28 \%$ increase in patients dismissed per unit time can be gained.

Baesler and Sepulveda [18] developed a methodology for a cancer treatment center in Florida, where a simulation model was incorporated in to a multi-objective optimization technique. They considered treatment chairs, the number of nurses who draw blood from patients, laboratory capacity, and pharmacy capacity as control variables. Four objectives were considered in this simulation optimization model. The objectives include minimization of patients waiting time and closing time, and maximization of chairs and nurse utilization. The resulted solutions of their approach was compared with the existing configuration of the system. They found an 18-25\% improvement of the solutions. Rosen et al. [19] developed a simulation optimization method that considers different performance measures.

In this research we have considered minimization of treatment cost and pain outcomes in our optimization model. Five pain outcomes have been considered. All of these pain outcomes are generated from questionnaires. Questionnaires are widely used to identify treatment outcomes in chronic pain. These types of questionnaires may consist of more than 300 questions, which is too long for the patients to complete. Huang et al.[20] used machine learning to find out the best 
subset of questions from the questionnaire. Their classification results shows the subsets have high relationships with treatment outcomes. Thus, they reduced irrelevant questions from the questionnaire for patients with pain. Ali et al. [21] developed an automated delivery system for clinical guidelines (DSCG) to assist physicians in diagnosing and treating patients with chest pain. These guidelines, which are selected from a knowledge based server, are used to improve efficiency in both diagnostic and treatment stages. The delivery system recommends optimal treatment plans based on most probable diagnosis, which improve patient outcomes. Computer based protocols in emergency departments have been used to forecast myocardial infarction. Goldman et al. [22] found that computer based protocols reduces the admission of patients to emergency department by $11.5 \%$.

\subsection{Piecewise Linear Network Model}

A piecewise linear network (PLN), shown in Figure 2.1, uses the divide and conquer approach in solving a problem. The input vector space is divided into several clusters, which comprise of a Voronoi tessellation. A linear mapping for each cluster is independently trained. The overall network is a piecewise linear mapping that may not be continuous [23]. PLN consists of $K$ cluster center vectors $m_{k}$, each of dimension $N$, where $1 \leq k \leq K$. There are $\mathrm{K}$ weight matrices $W_{k}$, each of dimension $M \times(N+1)$, for storing trained weights for each cluster. A weighted distance measure $d()$, which can be used to determine cluster membership for patterns while deemphasizing the less important features in the pattern vector. Weights for the distance measure are stored in an array $b$ of length $N$. The distance measure $d()$ is a function of two vectors and yields a value quantifying the distance between the two. Distance measures are used by clustering methods to determine proximity of patterns to each other, and by piecewise linear networks to select a network with which to process an incoming pattern. The weighted $L_{1}$ norm formula, $d(x, m)=\sum_{n=1}^{N} b(n)|x(n)-m(n)|$ can be used to calculate the distance measure.

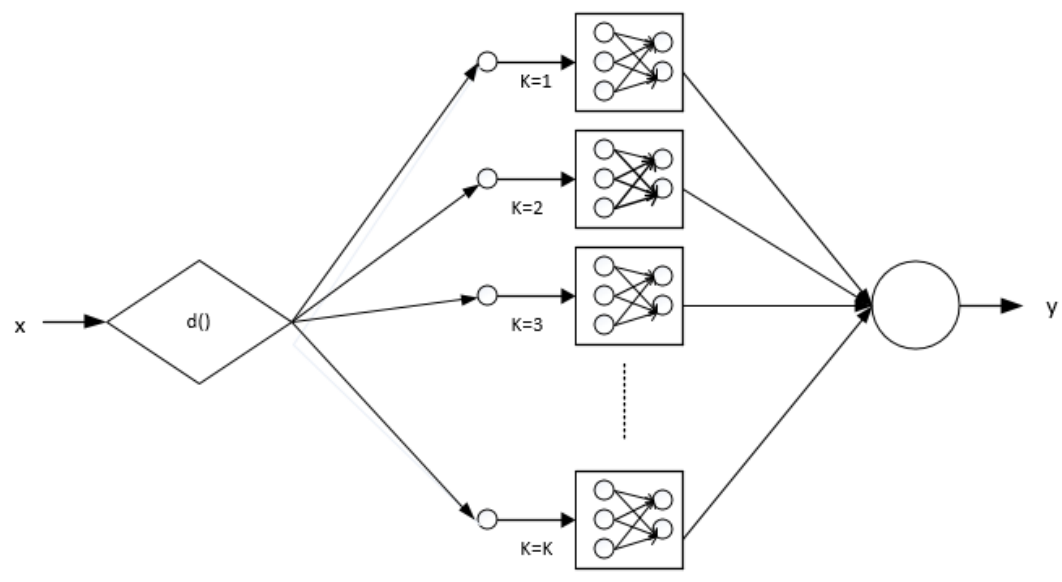

Figure 2.1: Structure of Piecewise Linear Network [23] 
Several research papers have been done in health care to develop state transition models using Piecewise linear network models. Matthews et al. [24] studied the changes in risk factors of coronary heart disease in midlife women using a piecewise linear model, which was consistent with ovarian aging, and a linear model, which was consistent with chronological aging. The piecewise linear model provided a better fit. Reynolds and Chiu [25] used a piecewise regression model in their study of understanding thermoregulatory transitions during hemorrhage in rats, where the model was constrained to the critical transition point.

\subsection{Contribution}

This research proposes a multi-objective two-stage stochastic programming (2SP) optimization approach to find optimal treatment strategies for adaptive pain management, where transition models, which have been used as constraints in the 2SP model are Piecewise Linear Network (PLN) models. We developed a mixed integer program to integrate these PLN models into the 2SP optimization. To see the relationship between different pain outcomes, we developed a survey, which shows the pairwise comparison of different levels of different pain outcomes. Pain management experts filled out the survey. However, the survey results are not entirely consistent because survey input is subjective and varies from expert to expert. To get weights to penalize different pain outcomes, we developed a convex quadratic programming model that attempts to find a consensus within the surveys.

Then we developed equivalent mixed integer linear programming (MILP) model by using some linearization techniques. We used AMPL/CPLEX to solve this MILP. Result shows that, the MILP gives optimal solution for most of the patients within 6 minutes. Then we compare the results with Wang's [14] results, who used regression approach to developed transition models. To speed up the solution process, we developed additional constraints based upon 3-way treatment interactions. These 3-way treatment interaction constraints are totally consistent with two-way treatment interaction constraints. These additional constraints do not eliminate real integer solutions, but they may eliminate fractional solutions in the branch-and-bound algorithm. We then solved the original MILP with these additional logical style constraints to see the improvement in MILP. 


\section{Chapter 3}

\section{Mathematical Model}

This chapter describes the mathematical models that have been used in this research to generate adaptive treatment strategies. Section 3.1 shows the formulation of two-stage stochastic programming. Convex quadratic programming formulation to get penalty weights is shown in section 3.2 . Section 3.3 discusses mixed integer linear programming formulation to integrate piece-wise linear network models into original optimization problem. Finally, section 3.4 discuss the linearization of three-way treatment interaction constraints.

\subsection{Stochastic Programming Formulation}

The goal of this research is to find adaptive treatment strategies for patients using a statisticsbased optimization approach. Treatments should be prescribed in such a way that can minimize a patient's pain outcome and treatment cost as well. The objective function consists of two parts-a penalty function of pain outcomes and a cost function of treatment usage. Let $P(\bullet)$ be the penalty function on pain outcomes and $C(\bullet)$ be the treatment cost function . Let $N$ be the set of pain outcomes (indexed by $i$ ), and $N_{i}$ is the set of levels of each pain outcome $i \in N$ (indexed by $j$ ). The penalty function of pain outcomes is used to keep pain within an acceptable limit. Let $u_{i j}$ be the penalty weights of pain outcome $i \in N$ for level $j \in N_{i}$. The purpose of the cost function in the objective is to put higher cost on treatment usage to avoid over medication. The cost function used in this research is from [14]. Parameter $\rho$ is a treatment cost coefficient, which is used to maintain a balance between the pain outcomes and the treatment cost function. Let variables $Y_{i 1}\left(\varepsilon_{i 1}\right)$ and $Y_{i 2}\left(\varepsilon_{i 1}, \varepsilon_{i 2}\right)$ be pain outcome $i$ in at stages 1 and 2 with uncertainties $\varepsilon_{i 1}$ and $\varepsilon_{i 2}$. Both uncertainties in stage 1 and stage 2 follow a normal distribution with mean 0 and some standard deviation. Let $x_{t}, x_{t}^{p}, s_{t}$ and $\Gamma_{t}$ be decision variables, type-p treatments, state variables, and feasible decision spaces at stage $t$, respectively. The set $\Lambda$ is the set of treatment interaction restrictions.

Traditional two-stage stochastic programming (2SP) optimization includes an objective function with potentially non-convex constraints (3.1a)-(3.1f). 2SP is a mixed integer non-linear programming model (MINLP), which is given below. 


$$
\begin{array}{rr}
\min : \sum_{i \in N} \sum_{j \in N_{i}} E\left(P_{u_{i j}}\left(Y_{i 2}\left(\varepsilon_{1}, \varepsilon_{2}\right)\right)\right)+\rho\left(\sum C\left(x_{1}\right)+\sum E\left(C\left(x_{2}\left(\varepsilon_{1}\right)\right)\right)\right) & \\
\text { subject to: } Y_{i 1}\left(\varepsilon_{i 1}\right)=h_{1}\left(s_{1}, x_{1}, \varepsilon_{i 1}\right) & \forall i \in N \\
Y_{i 2}\left(\varepsilon_{i 1}, \varepsilon_{i 2}\right)=h_{2}\left(s_{2}\left(\varepsilon_{i 1}\right), x_{2}\left(\varepsilon_{i 1}\right), \varepsilon_{i 2}\right) & \forall i \in N \\
x_{1}^{i} * x_{1}^{j}=0, x_{2}^{i}\left(\varepsilon_{1}\right) * x_{2}^{j}\left(\varepsilon_{1}\right)=0 & \forall\left(x^{i}, x^{j}\right) \in \Lambda \\
s_{2}\left(\varepsilon_{1}\right)=\left[s_{1}, x_{1}, Y_{1}\left(\varepsilon_{1}\right)\right] & \forall i \in N \\
x_{1} \in \Gamma_{1}, x_{2}\left(\varepsilon_{1}\right) \in \Gamma_{2} &
\end{array}
$$

Constraint set (3.1b) shows transition models for all pain outcomes at the end of stage 1, while constraint set (3.1c) is for transition models at the end of stage 2 for all pain outcomes. Equation (3.1d) ensures that some treatments that have adverse interaction are not assigned to patients simultaneously. The state variables in stage 2 include the set of stage 1 state variables, stage 1 decision variables, and pain outcomes of stage 1 , which is shown in equation (3.1e). This equation carries information from stage 1 to stage 2. Equation (3.1f) ensures that the decision variables in both stages 1 and 2 are within a feasible treatment region.

Using only constraint sets (3.1b) and (3.1c), it is possible that pain outcomes can be negative at the end of each stage. However, pain outcomes are non-negative in practice. Let $\bar{Y}_{i 1} \& \bar{Y}_{i 2}$ be truncating variables that are the maximum of each of $Y_{i 1} \& Y_{i 2}$ and 0 at the end of stage 1 and 2 for each pain outcome $i \in N$. These truncating variables, defined in (3.2b) \& (3.2c), make sure that non-negative pain outcomes are used in the next stage. We replaced final pain outcomes in (3.1a) by these truncating variables (4.1a).

$$
\begin{array}{rr}
\min : \sum_{i \in N} \sum_{j \in N_{i}} E\left(P_{u_{i j}}\left(\bar{Y}_{i 2}\left(\varepsilon_{1}, \varepsilon_{2}\right)\right)\right)+\rho\left(\sum C\left(x_{1}\right)+\sum E\left(C\left(x_{2}\left(\varepsilon_{1}\right)\right)\right)\right) & \\
\text { subject to: }(3.1 b)-(3.1 f) & \\
\bar{Y}_{i 1}\left(\varepsilon_{i 1}\right)=\max \left(0, Y_{i 1}\left(\varepsilon_{i 1}\right)\right) & \forall i \in N \\
\bar{Y}_{i 2}\left(\varepsilon_{i 1}, \varepsilon_{i 2}\right)=\max \left(0, Y_{i 2}\left(\varepsilon_{i 1}, \varepsilon_{i 2}\right)\right) & \forall i \in N
\end{array}
$$

\subsection{Convex Quadratic Programming Formulation to get Weights}

As mentioned previously, we have considered 5 pain outcomes in this research, which are OSW, PDA, BDI, sf36pcs, and sf36mcs. It is necessary to strike a balance between the different pain outcomes. We develop a survey to determine the relationships among these pain outcomes (Tables 3.6-3.9). The survey is a pairwise comparison of different levels of different pain outcomes. Pain Management experts filled out the survey to input the relationship between different levels of 
different pain outcomes. We acquire weights from multiple surveys and merge them to get consistent weights. However, the survey results are not consistent. To minimize survey inconsistency, we develop a convex quadratic programming model.

The following is a description of the sets used in the model.

- $N=$ the set of pain outcomes (indexed by $i$ ).

- $N_{i}=$ the set of levels of each pain outcome $i \in N$ (indexed by $j$ ).

- $Q=$ the set of surveys (indexed by $k$ )

The parameters used in the model are:

- $\sigma=$ a targeted weight ratio between consecutive levels of the same pain outcome.

- $\omega_{i j \hat{i} \hat{j} k}=$ the relative importance of $j$ th level of pain outcome $i$ with $\hat{j}$ th level of pain outcome $\hat{i}, \forall(i, \hat{i}) \in N, \hat{i}>i, j \in N_{i}, \hat{j} \in N_{\hat{i}}, k \in Q$.

The variables of the model are as follows:

- $u_{i j}=$ the weights of pain outcome $i \in N$ for level $j \in N_{i}$.

- $s_{i j}=$ the inconsistency of weights between consecutive levels of pain outcome $i$.

- $t_{i j \hat{i} \hat{j} k}=$ the inconsistency of the weights between the $j$ th level weight of pain outcome $i$ and $\hat{j}$ th level of pain outcome $\hat{i}, \forall(i, \hat{i}) \in N, \hat{i}>i, j \in N_{i}, \hat{j} \in N_{\hat{i}}, k \in Q$.

$$
\begin{aligned}
& \min \sum_{i \in N}\left(\sum_{j \in N_{i} \backslash\left\{\left|N_{i}\right|\right\}} s_{i j}^{2}+\sum_{j \in N_{i}} \sum_{\substack{i \in N \\
: i>i}} \sum_{\hat{j} \in N_{\hat{i}}} \sum_{k \in Q} t_{i j \hat{i} \hat{j} k}^{2}\right) \\
& \text { subject to: } \\
& 1 \leq u_{i 1} \\
& u_{i j} \leq u_{i(j+1)} \\
& \sigma u_{i j} \leq u_{i(j+1)}+s_{i j} \\
& \omega_{i j \hat{i} \hat{j} k} u_{i j}-u_{\hat{i} \hat{j}}=t_{i j \hat{j} \hat{j} k} \quad \forall(i, \hat{i}) \in N, \hat{i}>i, j \in N_{i}, \hat{j} \in N_{\hat{i}}, k \in Q \\
& u_{i j}, s_{i j}, t_{i j \hat{i} \hat{j} k} \geq 0 \quad \forall(i, \hat{i}) \in N, \hat{i}>i, j \in N_{i}, \hat{j} \in N_{\hat{i}}, k \in Q
\end{aligned}
$$

The objective is to minimize the inconsistency of the surveys. Constraint set (3.3b) shows that the first level weights of each pain outcome should be greater than or equal to 1 . Since we want to minimize pain outcomes for the patients, we put less weight on the lower levels of pain in the optimization model, while more weight is on higher levels of pain. Consequently, the weight 
for next level of pain should be greater than or equal to previous level for each pain outcome. Constraint set (3.3c) includes hard constraints, which ensure that the relationship of weight values between different levels for each pain outcome is non-decreasing. Constraint set (3.3d) includes soft constraints, which indicates that the consecutive levels within the same pain outcome should increase by at least $\sigma$. When this increase is unmet, the variable $s_{i j}$ is non-negative and penalized in the objective function. In the case study, we used $\sigma=3$. Constraint set (3.3e) shows that the $j$ th level weight of $i$ th pain outcome is $\omega_{i j \hat{i} \hat{j} k}$ times more important than the $\hat{j}$ th level of the $\hat{i}$ th pain outcome for each survey $k \in Q$. This pairwise comparison of different levels of different pain outcomes is treated as a soft constraint. Survey inconsistency $t_{i j \hat{i} \hat{j} k}$ is also included in constraint set (3.3e). Constraint set (3.3f) shows the bounds for decision variables.

\subsection{Mixed Integer Linear Programming for Piecewise Linear Net- work Models}

State transition models for pain outcomes, $h_{1}$ and $h_{2}$, are in constraints (3.1b) and (3.1c), in this two-stage stochastic programming optimization model. In this research, we use piecewise linear network (PLN) models to predict transitions. PLN models mitigate multicollinearity of multiple response variables by breaking up the space into multiple networks. Each network has a centroid and a set of linear regression models for the response variables. To determine the predicted responses for a set of independent variables, a weighted L1 distance measure determines to which network centroid the set of independent variables is closest. Then the linear regression models within the selected network determine the predicted responses. To incorporate these piecewise linear network transition models, in place of $h_{1}$ and $h_{2}$, into our optimization model, we must introduce additional MILP variables and constraints.

Consider the following sets, parameters, and variables. Let $N^{\prime}$ be the set of networks and $J^{\prime}$ be the set of variable features. Let parameter $x_{j^{\prime}}^{i^{\prime}}$ be the centroid value for network $i^{\prime}$ and feature $j^{\prime}$. For each $j^{\prime} \in J^{\prime}$, let decision variable $x_{j^{\prime}}$ be the value of feature $j^{\prime}$, and for each $i^{\prime} \in N^{\prime}$, let decision variables $y_{i^{\prime}}$ and $w_{i^{\prime} j^{\prime}}$ be binary variables such that

$$
y_{i^{\prime}}=\left\{\begin{array}{ll}
1 & \text { if } x_{j^{\prime}} \text { is in Network } i^{\prime} \\
0 & \text { otherwise }
\end{array} \quad w_{i^{\prime} j^{\prime}}= \begin{cases}1 & \text { if } x_{j^{\prime}} \geq x_{j^{\prime}}^{i^{\prime}} \\
0 & \text { otherwise }\end{cases}\right.
$$

For each network $i^{\prime} \in N^{\prime}$, each pain outcome $i \in N$, and each feature $j^{\prime} \in J^{\prime}$, let parameter $\beta_{i j^{\prime}}^{i^{\prime}}$ be the weight coefficient. Similarly, let $\beta_{i 0}^{i^{\prime}}$ be the intercept coefficient for each pain outcome $i \in N$ and each network $i^{\prime} \in N^{\prime}$. For each feature $j^{\prime} \in J^{\prime}$, let parameter $b_{j^{\prime}}$ be the distance measure weight. Let variable $Y_{i}$ be the outcome of the PLN transition models for each pain outcome $i \in N$, and parameter $M$ is a big number. For each network $i^{\prime} \in N^{\prime}$ and each feature $j^{\prime} \in J^{\prime}$, let variables $x_{j^{\prime}}^{i^{\prime}+}$ and $x_{j^{\prime}}^{i^{\prime}-}$ be the value of decision variable $x_{j^{\prime}}$, whether it is greater than or less than the centroid of network $i^{\prime}$, respectively. The MILP transition constraints can be formulated by the following: 


$$
\begin{array}{rr}
-M\left(1-y_{i^{\prime}}\right)+\beta_{i 0}^{i^{\prime}}+\sum_{j^{\prime} \in J^{\prime}} \beta_{j^{\prime}}^{i^{\prime}} x_{j^{\prime}}+\varepsilon_{i} \leq Y_{i} \leq \beta_{i 0}^{i^{\prime}} & \\
+\sum_{j^{\prime} \in J^{\prime}} \beta_{i j^{\prime}}^{i^{\prime}} x_{j^{\prime}}+\varepsilon_{i}+M\left(1-y_{i^{\prime}}\right) & \\
\sum_{i^{\prime} \in N^{\prime}} y_{i^{\prime}}=1 & \\
\sum_{j^{\prime} \in J^{\prime}} d_{i^{\prime} j^{\prime}} \leq \sum_{j^{\prime} \in J^{\prime}} d_{k^{\prime} j^{\prime}}+M\left(1-y_{i^{\prime}}\right) & \forall i \in N, i^{\prime} \in N^{\prime} \\
x_{j^{\prime}}^{i^{\prime}} w_{i^{\prime} j^{\prime}} \leq x_{j^{\prime}}^{i^{\prime}+} \leq M w_{i^{\prime} j^{\prime}} & \\
-M\left(1-w_{i^{\prime} j^{\prime}}\right) \leq x_{j^{\prime}}^{i^{\prime}-} \leq x_{j^{\prime}}^{i^{\prime}}\left(1-w_{i^{\prime} j^{\prime}}\right) & \left.\forall i^{\prime}, k^{\prime}\right) \in N^{\prime}, k^{\prime} \neq i^{\prime} \\
x_{j^{\prime}}=x_{j^{\prime}}^{i^{\prime}+}+x_{j^{\prime}}^{i^{\prime}-} & \forall i^{\prime} \in N^{\prime}, j^{\prime} \in J^{\prime} \\
d_{i^{\prime} j^{\prime}}=b_{j^{\prime}}\left(x_{j^{\prime}}^{i^{\prime}}-2 x_{j^{\prime}}^{i^{\prime}} w_{i^{\prime} j^{\prime}}+x_{j^{\prime}}^{i^{\prime}+}-x_{j^{\prime}}^{i^{\prime}-}\right) & \forall i^{\prime} \in N^{\prime}, j^{\prime} \in J^{\prime} \\
y_{i^{\prime}} \in\{0,1\} & \forall i^{\prime} \in N^{\prime}, j^{\prime} \in J^{\prime} \\
w_{i^{\prime} j^{\prime}} \in\{0,1\} & \forall i^{\prime} \in N^{\prime} \\
Y_{i}, x_{j^{\prime}}, x_{j^{\prime}}^{i^{\prime}+}, x_{j^{\prime}}^{i^{\prime}-} \in(-\infty,+\infty) & \forall i^{\prime} \in N^{\prime}, j^{\prime} \in J^{\prime}
\end{array}
$$

If the decision variables $x_{j^{\prime}}, j^{\prime} \in J^{\prime}$, are in network $i^{\prime}$ then constraint set (3.5a) ensures the pain outcomes $Y_{i}, i \in N$, are equal to the regression models within the network $i^{\prime}$; otherwise, a big $\mathrm{M}$ is used to relax the constraints (3.5a). Constraint (3.5b) guarantees only one network is used. Constraint set (3.5c) ensures that for each network pair $\left(i^{\prime}, k^{\prime}\right) \in N^{\prime}$ and each feature variable $j^{\prime} \in J^{\prime}$, the sum of the weighted distance variables $d_{i^{\prime} j^{\prime}}$, defined in equation $(3.5 \mathrm{~g})$, is less than or equal to the sum of the weighted distances of all other networks $k^{\prime}$ where $k^{\prime} \neq i^{\prime}$. Consequently, this constraint set determines the selected network. Constraints (3.5d)-(3.5f) link the decision variable $x_{j^{\prime}}$ to variables $x_{j^{\prime}}^{i^{\prime}+}$ and $x_{j^{\prime}}^{i^{\prime}-}$ based upon whether $x_{j^{\prime}}$ is greater than or less then centroid values $x_{j^{\prime}}^{i^{\prime}}$. Constraints $(3.5 \mathrm{a})-(3.5 \mathrm{j})$ can be used in place of constraints $(3.1 \mathrm{~b})$ and $(3.1 \mathrm{c})$. 


\subsection{Three-way Treatment Interaction Constraints}

A description of the treatment variables are shown in Table 3.1. From equation (3.1d) we see that treatment $i$ and $j$ cannot be assign simultaneously because of their adverse interaction. These twoway treatment interactions are shown in Table 3.2. Checkmark $(\checkmark)$ indicates they have no adverse interaction, and Crossmark $(\boldsymbol{X})$ means they have adverse interaction. However, it is well known in mathematical programming optimization that if additional logical style constraints can be added to an MILP problem, then often times the solution process is faster. These additional constraints do not eliminate real integer solutions, but they may eliminate fractional solutions in the branch-andbound algorithm. We then developed constraints based upon 3-way treatment interactions. These 3 -way treatment interaction constraints are totally consistent with two-way treatment interaction constraints. From table 3.2, we determine that three types of 3-way treatment interactions are possible. Table 3.3 shows the first type of 3 -way treatment interactions. For example, RxGr1 \& RxGr3 interact with each other, but they do not interact with RxGr2. Table 3.4 shows the second type of 3-way treatment interactions. For example, RxGr1 interacts with both RxGr3 \& RxGr7, but RxGr3 \& RxGr7 do not interact with each other. Table 3.5 shows the third type of 3-way treatment interaction. For example, RxGr1, RxGr3 \& RxGr4 all interact with each other. 
Table 3.1: Description of Variables

\begin{tabular}{|c|c|c|c|}
\hline $\begin{array}{l}\text { Variable } \\
\text { type }\end{array}$ & $\begin{array}{l}\text { Variable } \\
\text { Name }\end{array}$ & Description & Values \\
\hline \multirow{26}{*}{$\begin{array}{l}\text { State } \\
\text { Variables }\end{array}$} & pre_PDA & PDA measure at the initial point & Continuous \\
\hline & pre_OSW & OSW measure at the initial point & Continuous \\
\hline & pre_BDI & BDI measure at the initial point & Continuous \\
\hline & $\begin{array}{l}\text { pre_SF36- } \\
\text { pcs }\end{array}$ & SF36-pcs measure at the initial point & Continuous \\
\hline & $\begin{array}{l}\text { pre_SF36- } \\
\text { mcs }\end{array}$ & SF36-mcs measure at the initial point & Continuous \\
\hline & Age & Patient's age & Continuous \\
\hline & Children & Children & Continuous \\
\hline & Onset & Time (in months) since the first onset of pain & Continuous \\
\hline & Duration & Duration & Continuous \\
\hline & Status & Status of condition & $\begin{array}{l}1: \text { acute }(<3 \\
\text { months }), 2 \text { acute } \\
(<6 \text { months }) \text {, } \\
\text { 3:acute }(<\quad 9 \\
\text { months })\end{array}$ \\
\hline & Race_1 & Race of Patient & 0:no, 1:Caucasian \\
\hline & Race_2 & Race of Patient & $\begin{array}{l}\text { 0:no, 1:African } \\
\text { American }\end{array}$ \\
\hline & Litigate & Pending litigation related to pain? & 0:no, 1:yes \\
\hline & Gender & Patient's gender & 0:male, 1:female \\
\hline & phydx1 & Physical Dx1/Facial 784.0 & 0:no, 1:yes \\
\hline & phydx3 & Physical Dx3/Headache 784.0 & 0:no, 1:yes \\
\hline & phydx4 & Physical Dx4/Cervical 723.1 & 0:no, 1:yes \\
\hline & phydx5 & Physical Dx5/Thoracic 724.1 & 0:no, 1:yes \\
\hline & phydx6 & Physical Dx6/Lumbar 724.2 & 0:no, 1:yes \\
\hline & phydx7 & Physical Dx7/Myofascial-Fibromyalgia 729.1 & 0:no, 1:yes \\
\hline & phydx8 & Physical Dx8/Abdominal 789.0 & 0:no, 1:yes \\
\hline & phydx11 & Physical Dx11/Upper Extremity 729.5 & 0:no, 1:yes \\
\hline & phydx12 & Physical Dx12/Low Extremity 729.5 & 0:no, 1:yes \\
\hline & phydx14 & Physical Dx14/Osteoarthritis 716.9 & 0:no, 1:yes \\
\hline & phydx15 & Physical Dx15/Sacro-illitis 724.6 & 0:no, 1:yes \\
\hline & phydx20 & $\begin{array}{l}\text { Physical Dx20/Neuralgia, Neuritis, Unspeci- } \\
\text { fied }\end{array}$ & 0:no, 1:yes \\
\hline
\end{tabular}

Continued on next page 
Table 3.1 - Continued from previous page

\begin{tabular}{|c|c|c|c|}
\hline $\begin{array}{l}\text { Variable } \\
\text { type }\end{array}$ & $\begin{array}{l}\text { Variable } \\
\text { Name }\end{array}$ & Description & Values \\
\hline & phydx31 & $\begin{array}{l}\text { Physical Dx/Cervical Spondylosis } \mathrm{W} / \mathrm{O} \\
\text { Myelopathy (721.0) }\end{array}$ & 0:no, 1:yes \\
\hline & ProcGr1_0 & Injection in stage 0 & 0:no, 1:yes \\
\hline & ProcGr2_0 & Block Procedure in stage 0 & 0:no, 1:yes \\
\hline & ProcGr4_0 & Stimulation Procedure in stage 0 & 0:no, 1:yes \\
\hline & ProcGr9_0 & Psychotherapy in stage 0 & 0:no, 1:yes \\
\hline & ProcGr10_0 & Physical Therapy in stage 0 & 0:no, 1:yes \\
\hline & ProcGr11_0 & Number of Additional Procedures in stage 0 & 0:no, 1:yes \\
\hline & pastdx3 & Past Dx3/Headache 784.0 & 0:no, 1:yes \\
\hline & pastdx 4 & Past Dx4/Cervical 723.1 & 0:no, 1:yes \\
\hline & pastdx 5 & Past Dx5/Thoracic 724.1 & 0:no, 1:yes \\
\hline & pastdx6 & Past Dx6/Lumbar 724.2 & 0:no, 1:yes \\
\hline & pastdx7 & Past Dx7/Myofascial-Fibromyalgia 729.1 & 0:no, 1:yes \\
\hline & pastdx 8 & Past Dx8/Abdominal 789.0 & 0:no, 1:yes \\
\hline & pastdx11 & Past Dx11/Upper Extremity 729.5 & 0:no, 1:yes \\
\hline & pastdx12 & Past Dx12/Low Extremity 729.5 & 0:no, 1:yes \\
\hline & pastdx14 & Past Dx14/Osteoarthritis 716.9 & 0:no, 1:yes \\
\hline & pastdx15 & Past Dx15/Sacro-illitis 724.6 & 0:no, 1:yes \\
\hline & pastdx20 & Past Dx20/Neuralgia, Neuritis, Unspecified & 0:no, 1:yes \\
\hline & pastdx32 & Past Dx/Number of Additional Diagnoses & 0:no, 1:yes \\
\hline & SghxGr1 & Surgical History/Unspecified discectomy & 0:no, 1:yes \\
\hline & SghxGr3 & Surgical History/Percutaneous discectomy & 0:no, 1:yes \\
\hline & SghxGr5 & Surgical History/Unspecified fusion & 0:no, 1:yes \\
\hline & SghxGr6 & Surgical History/Anterior fusion & 0:no, 1:yes \\
\hline & SghxGr11 & Surgical History/Hardware removal & 0:no, 1:yes \\
\hline & RxGr1_0 & Tramadol in stage 0 & $0:$ no, $1,2,3$ \\
\hline & RxGr2_0 & NSAIDs in stage 0 & $0:$ no, $1,2,3$ \\
\hline & RxGr3_0 & Narcotic in stage 0 & $0:$ no, $1,2,3$ \\
\hline & RxGr4_0 & Muscle Relaxant in stage 0 & $0:$ no, $1,2,3$ \\
\hline & RxGr5_0 & Antidepressant in stage 0 & $0:$ no, $1,2,3$ \\
\hline & RxGr6_0 & Tranquilizer in stage 0 & $0:$ no, $1,2,3$ \\
\hline & RxGr7_0 & Sleeping Pills in stage 0 & $0:$ no, $1,2,3$ \\
\hline & RxGr8_0 & Others in stage 0 & $0:$ no, $1,2,3$ \\
\hline & marital_1 & Marital Status of Patient & 0:no, 1:single \\
\hline & marital_2 & Marital Status of Patient & 0:no, 1:married \\
\hline
\end{tabular}


Table 3.1 - Continued from previous page

\begin{tabular}{|c|c|c|c|}
\hline $\begin{array}{l}\text { Variable } \\
\text { type }\end{array}$ & $\begin{array}{l}\text { Variable } \\
\text { Name }\end{array}$ & Description & Values \\
\hline & marital_3 & Marital Status of Patient & 0:no, 1:divorced \\
\hline & marital_4 & Marital Status of Patient & 0:no, 1:widow \\
\hline \multirow{27}{*}{$\begin{array}{l}\text { Decision } \\
\text { Variables }\end{array}$} & ProcGr1_1 & Injection in stage 1 & 0:no, 1:yes \\
\hline & ProcGr2_1 & Block Procedure in stage 1 & 0:no, 1:yes \\
\hline & ProcGr4_1 & Stimulation Procedure in stage 1 & 0:no, 1:yes \\
\hline & ProcGr9_1 & Psychotherapy in stage 1 & 0:no, 1:yes \\
\hline & ProcGr10_1 & Physical Therapy in stage 1 & 0:no, 1:yes \\
\hline & ProcGr11_1 & Number of Additional Procedures in stage 1 & 0:no, 1:yes \\
\hline & RxGr1_1 & Tramadol in stage 1 & $0:$ no, 1,2 \\
\hline & RxGr2_1 & NSAIDs in stage 1 & 0:no, $1,2,3$ \\
\hline & RxGr3_1 & Narcotic in stage 1 & $0:$ no, $1,2,3$ \\
\hline & RxGr4_1 & Muscle Relaxant in stage 1 & $0:$ no, $1,2,3$ \\
\hline & RxGr5_1 & Antidepressant in stage 1 & $0:$ no, $1,2,3$ \\
\hline & RxGr6_1 & Tranquilizer in stage 1 & $0:$ no, $1,2,3$ \\
\hline & RxGr7_1 & Sleeping Pills in stage 1 & $0:$ no, 1,2 \\
\hline & RxGr8_1 & Others in stage 1 & $0:$ no, 1,2 \\
\hline & ProcGr1_2 & Injection in stage 2 & 0:no, 1:yes \\
\hline & ProcGr2_2 & Block Procedure in stage 2 & 0:no, 1:yes \\
\hline & ProcGr4_2 & Stimulation Procedure in stage 2 & 0:no, 1:yes \\
\hline & ProcGr9_2 & Psychotherapy in stage 2 & 0:no, 1:yes \\
\hline & ProcGr10_2 & Physical Therapy in stage 2 & 0:no, 1:yes \\
\hline & RxGr1_2 & Tramadol in stage 2 & $0:$ no, $1,2,3$ \\
\hline & RxGr2_2 & NSAIDs in stage 2 & 0:no, $1,2,3$ \\
\hline & RxGr3_2 & Narcotic in stage 2 & $0:$ no, $1,2,3$ \\
\hline & RxGr4_2 & Muscle Relaxant in stage 2 & $0:$ no, $1,2,3$ \\
\hline & RxGr5_2 & Antidepressant in stage 2 & $0:$ no, $1,2,3$ \\
\hline & RxGr6_2 & Tranquilizer in stage 2 & 0:no, $1,2,3$ \\
\hline & RxGr7_2 & Sleeping Pills in stage 2 & $0:$ no, 1,2 \\
\hline & RxGr8_2 & Others in stage 2 & $0:$ no, $1,2,3$ \\
\hline
\end{tabular}


Table 3.2: Two-way Treatment Interaction Table

\begin{tabular}{c|c|c|c|c|c|c|c|c|c|c} 
& RxGr1 & RxGr2 & RxGr3 & RxGr4 & RxGr5 & RxGr6 & RxGr7 & RxGr8 & ProcGr1 & ProcGr2 \\
\hline RxGr1 & & $\checkmark$ & $\boldsymbol{x}$ & $\boldsymbol{x}$ & $\boldsymbol{x}$ & $\boldsymbol{x}$ & $\boldsymbol{x}$ & $\checkmark$ & $\boldsymbol{x}$ & $\checkmark$ \\
\hline RxGr2 & & & $\checkmark$ & $\checkmark$ & $\checkmark$ & $\boldsymbol{x}$ & $\checkmark$ & $\boldsymbol{x}$ & $\boldsymbol{x}$ & $\boldsymbol{x}$ \\
\hline RxGr3 & & & $\boldsymbol{x}$ & $\boldsymbol{x}$ & $\boldsymbol{x}$ & $\checkmark$ & $\checkmark$ & $\checkmark$ & $\checkmark$ \\
\hline RxGr4 & & & & & $\checkmark$ & $\boldsymbol{x}$ & $\boldsymbol{x}$ & $\boldsymbol{x}$ & $\checkmark$ & $\checkmark$ \\
\hline RxGr5 & & & & & $\boldsymbol{x}$ & $\boldsymbol{x}$ & $\checkmark$ & $\boldsymbol{x}$ & $\boldsymbol{x}$ \\
\hline RxGr6 & & & & & & $\boldsymbol{x}$ & $\checkmark$ & $\checkmark$ & $\checkmark$ \\
\hline RxGr7 & & & & & & & $\boldsymbol{x}$ & $\checkmark$ & $\checkmark$ \\
\hline RxGr8 & & & & & & & & & $\boldsymbol{x}$ & $\boldsymbol{x}$ \\
\hline
\end{tabular}

Table 3.3: Three-way treatment interaction:Type I

\begin{tabular}{|c|c|}
\hline RxGr2 & $\begin{aligned} \text { (RxGr1, RxGr3), } & (\text { RxGr1, RxGr4), (RxGr1, RxGr5) } \\
& (\text { RxGr1, RxGr7) }\end{aligned}$ \\
\hline RxGr3 & (RxGr2, RxGr8), (RxGr2, ProcGr1), (RxGr2, ProcGr2) \\
\hline RxGr5 & $(\mathrm{RxGr} 4, \mathrm{RxGr} 8)$ \\
\hline RxGr7 & (RxGr2, ProcGr1), (RxGr2, ProcGr2) \\
\hline RxGr8 & $(\mathrm{RxGr} 5, \mathrm{RxGr6})$ \\
\hline ProcGr1 & (RxGr3, RxGr4), (RxGr6, RxGr7) \\
\hline ProcGr2 & (RxGr3, RxGr4), (RxGr6, RxGr7) \\
\hline
\end{tabular}

\subsubsection{Linearization of Continuous Treatment Interaction Constraints}

First, we consider treatment interaction variables as continuous as shown in Figure 3.1. Then the linearization techniques are as follows. For all $\left(x_{i}, x_{j}, x_{k}\right) \in \Lambda$, let parameter $l_{i}, l_{j}$, and $l_{k}$ and $u_{i}$, $u_{j}$, and $u_{k}$ be the lower and upper bound of decision variables $x_{i}, x_{j}$, and $x_{k}$ in both stages, and let decision variables $w_{i}^{\prime}, w_{j}^{\prime}$, and $w_{k}^{\prime}$ be binary variables such that

$$
w_{i}^{\prime}=\left\{\begin{array}{ll}
1 & \text { if } x_{i} \geq 1 \\
0 & \text { otherwise }
\end{array} \quad w_{j}^{\prime}=\left\{\begin{array}{ll}
1 & \text { if } x_{j} \geq 1 \\
0 & \text { otherwise }
\end{array} \quad w_{k}^{\prime}= \begin{cases}1 & \text { if } x_{k} \geq 1 \\
0 & \text { otherwise }\end{cases}\right.\right.
$$

Original Two-Way Interaction: Suppose $x_{i}$ and $x_{j}$ interact with each other, then

Table 3.4: Three-way treatment interaction:Type II

\begin{tabular}{|c|c|}
\hline RxGr1 & $\begin{array}{c}\text { RxGr3, RxGr7), (RxGr3, ProcGr1), (RxGr4, RxGr5) } \\
\text { (RxGr4, ProcGr1), (RxGr6, ProcGr1) }\end{array}$ \\
\hline RxGr2 & $\begin{array}{c}\text { (RxGr6, RxGr8), (RxGr6, ProcGr1), (RxGr6, ProcGr2) } \\
\text { (ProcGr1, ProcGr2) }\end{array}$ \\
\hline RxGr3 & (RxGr4, RxGr5) \\
\hline RxGr4 & (RxGr6, RxGr8) \\
\hline RxGr5 & $\begin{array}{c}\text { (RxGr6, ProcGr1), (RxGr6, ProcGr2), (RxGr7, ProcGr1) } \\
\text { (RxGr7, ProcGr2) }\end{array}$ \\
\hline RxGr8 & (ProcGr1, ProcGr2) \\
\hline
\end{tabular}


Table 3.5: Three-way treatment interaction:Type III

\begin{tabular}{|c|c|}
\hline RxGr1 & $\begin{array}{c}\text { (RxGr3, RxGr4), (RxGr3, RxGr5), (RxGr3, ProcGr6) } \\
\text { (RxGr4, RxGr6), (RxGr4, RxGr7), (RxGr5, RxGr7) } \\
\text { (RxGr5, ProcGr1), (RxGr6, RxGr7) }\end{array}$ \\
\hline RxGr2 & (RxGr8, ProcGr1), (RxGr8, ProcGr2) \\
\hline RxGr3 & (RxGr4, RxGr6), (RxGr5, RxGr6) \\
\hline RxGr4 & (RxGr6, RxGr7), (RxGr7, RxGr8) \\
\hline RxGr5 & (RxGr6, RxGr7) \\
\hline
\end{tabular}

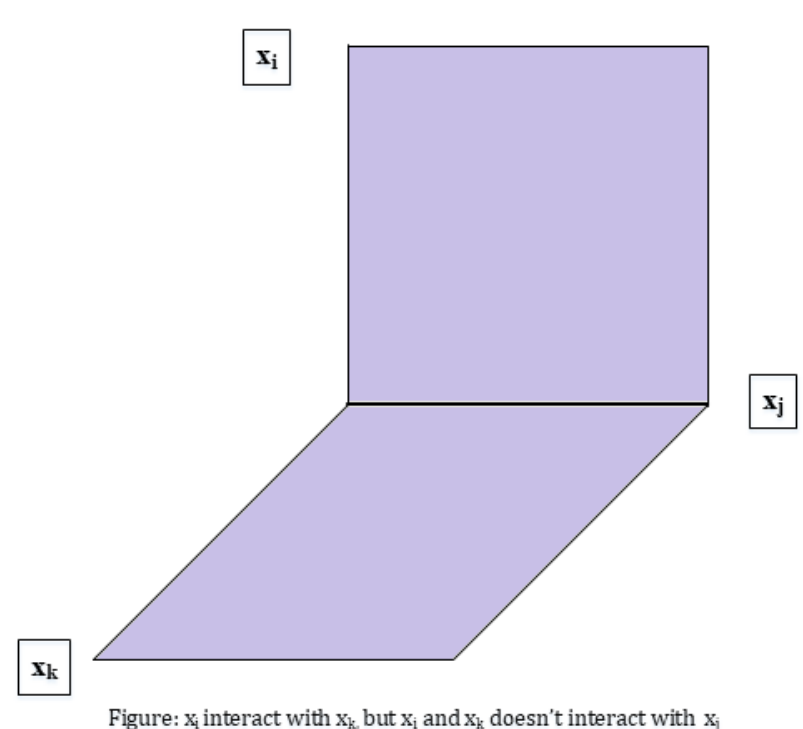

(a) $x_{i}$ interact with $x_{k}$, but $x_{i}$ and $x_{k}$ doesn't interact with $x_{j}$. The shaded region is feasible.

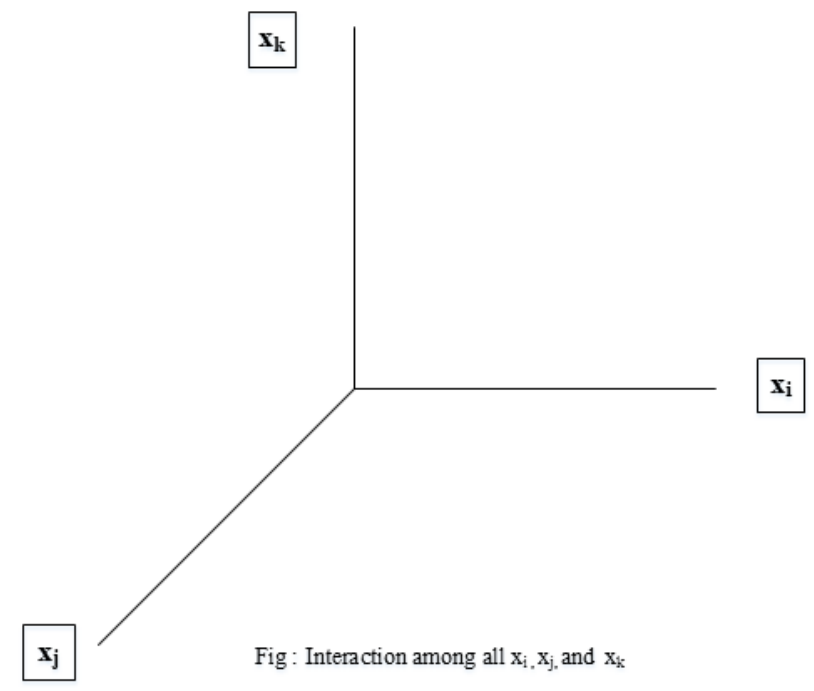

(c) $x_{i}, x_{j}$, and $x_{k}$ interact among all. Only the axis are feasible.

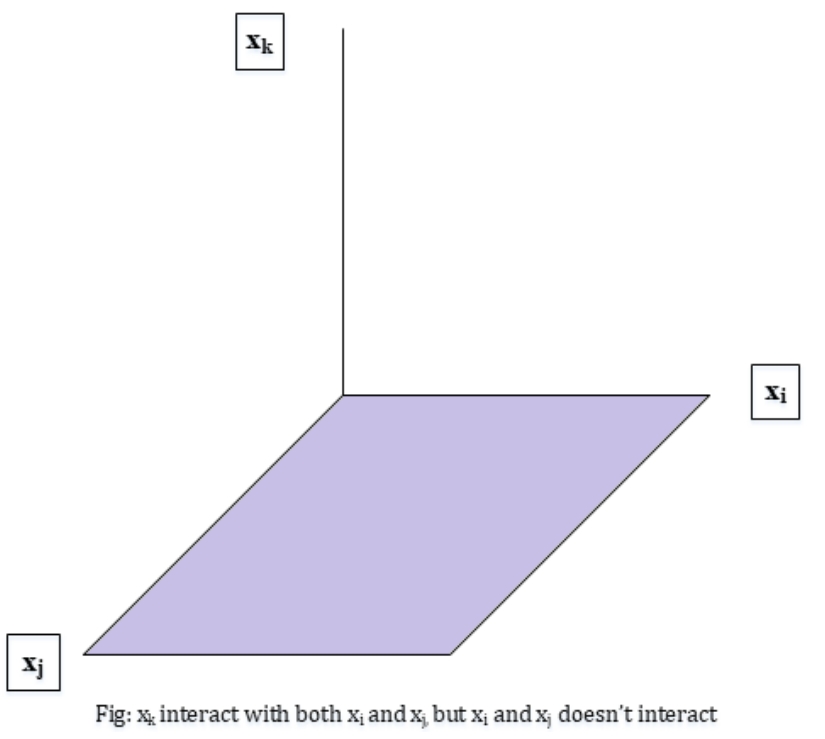

(b) $x_{k}$ interact with both $x_{i}$ and $x_{j}$, but $x_{i}$ and $x_{j}$ does not interact. The shaded region and the $x_{k}$ axis are feasible.

Figure 3.1: Three-way treatment interaction: Continuous 


$$
x_{i}-l_{i} \leq w_{i}^{\prime}\left(u_{i}-l_{i}\right), \quad x_{j}-l_{j} \leq w_{j}^{\prime}\left(u_{j}-l_{j}\right), \quad w_{i}^{\prime}+w_{j}^{\prime} \leq 1 .
$$

Three-way Type I: Suppose $x_{i}$ interacts with $x_{k}$, but $x_{i}$ and $x_{k}$ do not interact with $x_{j}$, then $x_{i}-l_{i} \leq w_{i}^{\prime}\left(u_{i}-l_{i}\right), \quad x_{j}-l_{j} \leq w_{j}^{\prime}\left(u_{j}-l_{j}\right), \quad x_{k}-l_{k} \leq w_{k}^{\prime}\left(u_{k}-l_{k}\right), \quad 2 w_{i}^{\prime}+w_{j}^{\prime}+2 w_{k}^{\prime} \leq 3$.

Three-way Type II: Suppose $x_{k}$ interacts with both $x_{i}$ and $x_{j}$, but $x_{i}$ and $x_{j}$ do not interact, then

$x_{i}-l_{i} \leq w_{i}^{\prime}\left(u_{i}-l_{i}\right), \quad x_{j}-l_{j} \leq w_{j}^{\prime}\left(u_{j}-l_{j}\right), \quad x_{k}-l_{k} \leq w_{k}^{\prime}\left(u_{k}-l_{k}\right), \quad w_{i}^{\prime}+w_{j}^{\prime}+2 w_{k}^{\prime} \leq 2$.

Three-way Type III: Suppose $x_{i}, x_{j}$, and $x_{k}$ all interact with each other (i.e. a three-way interaction), then $x_{i}-l_{i} \leq w_{i}^{\prime}\left(u_{i}-l_{i}\right), \quad x_{j}-l_{j} \leq w_{j}^{\prime}\left(u_{j}-l_{j}\right), \quad x_{k}-l_{k} \leq w_{k}^{\prime}\left(u_{k}-l_{k}\right), \quad w_{i}^{\prime}+w_{j}^{\prime}+w_{k}^{\prime} \leq 1$.

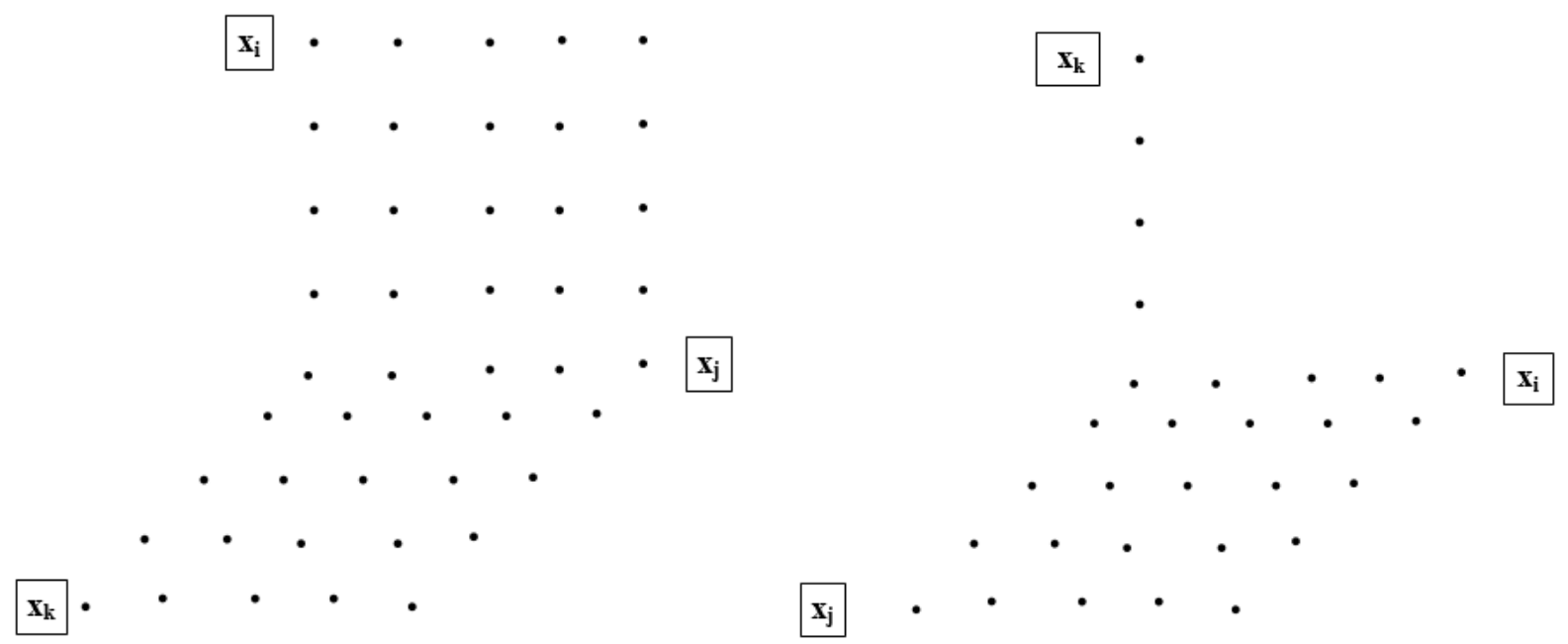

(a) $x_{i}$ interact with $x_{k}$, but $x_{i}$ and $x_{k}$ doesn't interact (b) $x_{k}$ interact with both $x_{i}$ and $x_{j}$, but $x_{i}$ and $x_{j}$ with $x_{j}$. does not interact.

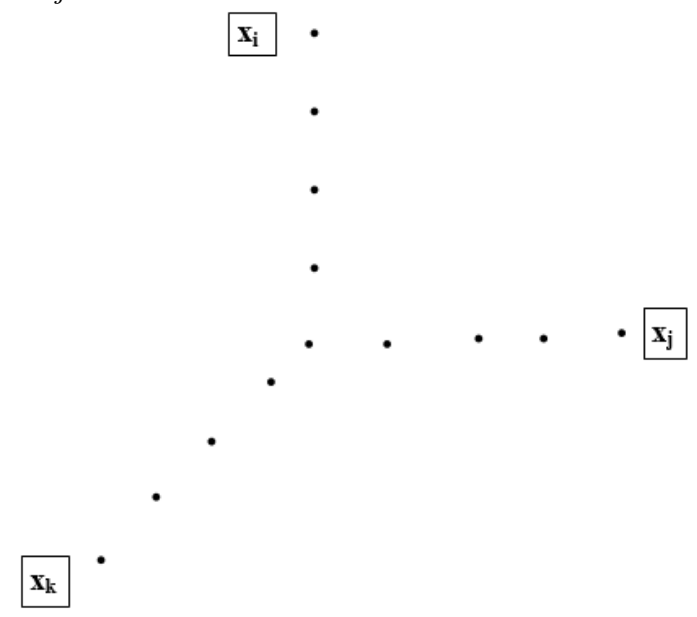

(c) $x_{i}, x_{j}$, and $x_{k}$ interact among all.

Figure 3.2: Three-way treatment interaction: Integer 


\subsubsection{Linearization of Integer Treatment Interaction Constraints}

In Section, we assumed that the treatment variables were continuous. However, many treatments are prescribed at certain discrete levels. In this section, we assume that the treatments are discrete integer variables. Figure 3.2 shows the corresponding feasible regions of each type of three way interaction with discrete treatment variables. Consider the following linearization techniques. Let $r_{i}$ be the set of discrete integer levels for treatment $i$ in feasible decision space in $\Gamma$. For all $i \in \Gamma$ and $p \in r_{i}$, let $x_{i p}$ be a binary variable such that,

$$
x_{i p}= \begin{cases}1 & \text { if treatement } i \text { is treated at level } p \\ 0 & \text { otherwise }\end{cases}
$$

Original Two-way: Suppose $x_{i}$ and $x_{j}$ interact with each other, then $\forall i \in \Gamma,(i, j) \in \Lambda, i \neq j$

$$
\sum_{p \in r_{i}} x_{i p}=1, \quad x_{i}=\sum_{p \in r_{i}} p x_{i p}, \quad \sum_{p \in r_{i} \backslash 0} x_{i p}+\sum_{q \in r_{j} \backslash 0} x_{j q} \leq 1 .
$$

Three-way Type I: Suppose $x_{i}$ interacts with $x_{k}$, but $x_{i}$ and $x_{k}$ do not interact with $x_{j}$, then $\forall i \in \Gamma,(i, j, k) \in \Lambda, i \neq j \neq k$

$\sum_{p \in r_{i}} x_{i p}=1, \quad x_{i}=\sum_{p \in r_{i}} p x_{i p}, \quad 2 \sum_{p \in r_{i} \backslash 0} x_{i p}+\sum_{q \in r_{j} \backslash 0} x_{j q}+2 \sum_{r \in r_{k} \backslash 0} x_{k r} \leq 3$.

Three-way Type II: Suppose $x_{k}$ interacts with both $x_{i}$ and $x_{j}$, but $x_{i}$ and $x_{j}$ do not interact, then $\forall i \in \Gamma,(i, j, k) \in \Lambda, i \neq j \neq k$

$$
\sum_{p \in r_{i}} x_{i p}=1, \quad x_{i}=\sum_{p \in r_{i}} p x_{i p}, \quad \sum_{p \in r_{i} \backslash 0} x_{i p}+\sum_{q \in r_{j} \backslash 0} x_{j q} \leq 2 x_{k 0} .
$$

Three-wayType III: Suppose $x_{i}, x_{j}$, and $x_{k}$ have a three-way interaction, then $\forall i \in \Gamma,(i, j, k) \in$ $\Lambda, i \neq j \neq k$ $\sum_{p \in r_{i}} x_{i p}=1, \quad x_{i}=\sum_{p \in r_{i}} p x_{i p}, \quad \sum_{p \in r_{i} \backslash 0} x_{i p}+\sum_{q \in r_{j} \backslash 0} x_{j q}+\sum_{r \in r_{k} \backslash 0} x_{k r} \leq 1$. 
Table 3.6: Questionnaire for OSW vs. PDA

\begin{tabular}{|c|c|c|c|c|c|c|c|}
\hline \multirow[t]{2}{*}{$\begin{array}{l}\text { Objective } \\
\text { Pairs }\end{array}$} & \multicolumn{2}{|c|}{ Pain outcome level } & \multirow{2}{*}{$\begin{array}{l}\text { If pain out- } \\
\text { come level } \\
\text { (a) and (b) } \\
\text { are equally } \\
\text { impor- } \\
\text { tant, then } \\
\text { check this } \\
\text { column. }\end{array}$} & \multicolumn{4}{|c|}{$\begin{array}{l}\text { If one is important than other one between (a) and (b), } \\
\text { then check the important one in pain outcome level col- } \\
\text { umn. After that check one of the columns from below } \\
\text { to show how important that checked pain outcome level } \\
\text { compare to other one. }\end{array}$} \\
\hline & (a) & (b) & & $\begin{array}{l}\text { Slightly } \\
\text { more im- } \\
\text { portant }\end{array}$ & $\begin{array}{l}\text { moderately } \\
\text { more impor- } \\
\text { tant }\end{array}$ & $\begin{array}{l}\text { strongly } \\
\text { more } \\
\text { important }\end{array}$ & $\begin{array}{l}\text { extremely } \\
\text { more } \\
\text { important }\end{array}$ \\
\hline \multirow{5}{*}{$\begin{array}{l}\text { OSW }(0-10) \\
\text { vs. PDA }\end{array}$} & $\square$ OSW $(0-10)$ & $\square \operatorname{PDA}(0-2)$ & $\square$ & $\square$ & $\square$ & $\square$ & $\square$ \\
\hline & $\square$ OSW $(0-10)$ & $\square$ PDA $(3-4)$ & $\square$ & $\square$ & $\square$ & $\square$ & $\square$ \\
\hline & $\square$ OSW $(0-10)$ & $\square$ PDA(5-6) & $\square$ & $\square$ & $\square$ & $\square$ & $\square$ \\
\hline & $\square$ OSW $(0-10)$ & $\square \operatorname{PDA}(7-8)$ & $\square$ & $\square$ & $\square$ & $\square$ & $\square$ \\
\hline & $\square$ OSW $(0-10)$ & $\square$ PDA(9-10) & $\square$ & $\square$ & $\square$ & $\square$ & $\square$ \\
\hline \multirow{5}{*}{$\begin{array}{l}\text { OSW(11- } \\
20) \text { vs. } \\
\text { PDA }\end{array}$} & $\square$ OSW(11-20) & $\square \operatorname{PDA}(0-2)$ & $\square$ & $\square$ & $\square$ & $\square$ & $\square$ \\
\hline & $\square$ OSW $(11-20)$ & $\square$ PDA(3-4) & $\square$ & $\square$ & $\square$ & $\square$ & $\square$ \\
\hline & $\square$ OSW $(11-20)$ & $\square$ PDA(5-6) & $\square$ & $\square$ & $\square$ & $\square$ & $\square$ \\
\hline & $\square$ OSW $(11-20)$ & $\square \operatorname{PDA}(7-8)$ & $\square$ & $\square$ & $\square$ & $\square$ & $\square$ \\
\hline & $\square$ OSW $(11-20)$ & $\square$ PDA $(9-10)$ & $\square$ & $\square$ & $\square$ & $\square$ & $\square$ \\
\hline \multirow{5}{*}{$\begin{array}{l}\text { OSW }(21- \\
30) \text { vs. } \\
\text { PDA }\end{array}$} & $\square$ OSW(21-30) & $\square$ PDA $(0-2)$ & $\square$ & $\square$ & $\square$ & $\square$ & $\square$ \\
\hline & $\square$ OSW $(21-30)$ & $\square$ PDA $(3-4)$ & $\square$ & $\square$ & $\square$ & $\square$ & $\square$ \\
\hline & $\square$ OSW $(21-30)$ & $\square$ PDA(5-6) & $\square$ & $\square$ & $\square$ & $\square$ & $\square$ \\
\hline & $\square$ OSW $(21-30)$ & $\square \operatorname{PDA}(7-8)$ & $\square$ & $\square$ & $\square$ & $\square$ & $\square$ \\
\hline & $\square$ OSW $(21-30)$ & $\square \operatorname{PDA}(9-10)$ & $\square$ & $\square$ & $\square$ & $\square$ & $\square$ \\
\hline \multirow{5}{*}{$\begin{array}{l}\text { OSW(31- } \\
40) \text { vs. } \\
\text { PDA }\end{array}$} & $\square$ OSW $(31-40)$ & 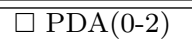 & 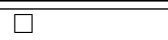 & $\bar{\square}$ & $\bar{\square} \square$ & $\bar{\square} \square$ & 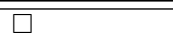 \\
\hline & $\square$ OSW $(31-40)$ & $\square$ PDA $(3-4)$ & $\square$ & $\square$ & $\square$ & $\square$ & $\square$ \\
\hline & $\square$ OSW $(31-40)$ & $\square$ PDA(5-6) & $\square$ & $\square$ & $\square$ & $\square$ & $\square$ \\
\hline & $\square$ OSW $(31-40)$ & $\square \operatorname{PDA}(7-8)$ & $\square$ & $\square$ & $\square$ & $\square$ & $\square$ \\
\hline & $\square$ OSW $(31-40)$ & $\square$ PDA $(9-10)$ & $\square$ & $\square$ & $\square$ & $\square$ & $\square$ \\
\hline \multirow{5}{*}{$\begin{array}{l}\text { OSW(41- } \\
50) \text { vs. } \\
\text { PDA }\end{array}$} & $\square$ OSW(41-50) & $\square$ PDA(0-2) & $\bar{\square} \square$ & $\bar{\square} \square$ & $\bar{\square} \square$ & $\bar{\square} \square$ & $\square$ \\
\hline & $\square$ OSW(41-50) & $\square$ PDA $(3-4)$ & $\square$ & $\square$ & $\square$ & $\square$ & $\square$ \\
\hline & $\square$ OSW $(41-50)$ & $\square \operatorname{PDA}(5-6)$ & $\square$ & $\square$ & $\square$ & $\square$ & $\square$ \\
\hline & $\square$ OSW $(41-50)$ & $\square \operatorname{PDA}(7-8)$ & $\square$ & $\square$ & $\square$ & $\square$ & $\square$ \\
\hline & $\square$ OSW $(41-50)$ & $\square \operatorname{PDA}(9-10)$ & $\square$ & $\square$ & $\square$ & $\square$ & $\square$ \\
\hline
\end{tabular}

Table 3.7: Questionnaire for OSW vs. sf36pcs

\begin{tabular}{|c|c|c|c|c|c|c|c|}
\hline \multirow[t]{2}{*}{$\begin{array}{l}\text { Objective } \\
\text { Pairs }\end{array}$} & \multicolumn{2}{|c|}{ Pain outcome level } & \multirow{2}{*}{$\begin{array}{l}\text { If pain out- } \\
\text { come level } \\
\text { (a) and (b) } \\
\text { are equally } \\
\text { impor- } \\
\text { tant, then } \\
\text { check this } \\
\text { column. }\end{array}$} & \multicolumn{4}{|c|}{$\begin{array}{l}\text { If one is important than other one between (a) and (b), } \\
\text { then check the important one in pain outcome level col- } \\
\text { umn. After that check one of the columns from below } \\
\text { to show how important that checked pain outcome level } \\
\text { compare to other one. }\end{array}$} \\
\hline & (a) & (b) & & $\begin{array}{l}\text { Slightly } \\
\text { more im- } \\
\text { portant }\end{array}$ & $\begin{array}{l}\text { moderately } \\
\text { more impor- } \\
\text { tant }\end{array}$ & $\begin{array}{l}\text { strongly } \\
\text { more } \\
\text { important }\end{array}$ & $\begin{array}{l}\text { extremely } \\
\text { more } \\
\text { important }\end{array}$ \\
\hline \multirow{2}{*}{$\begin{array}{l}\text { OSW }(0-10) \text { vs. } \\
\text { sf36pcs }\end{array}$} & $\square$ OSW(0-10) & $\square$ sf36pcs $\geq 50)$ & $\bar{\square}$ & $\square$ & $\bar{\square}$ & $\bar{\square}$ & $\bar{\square}$ \\
\hline & $\square$ OSW $(0-10)$ & $\square \mathrm{sf36pcs<50)}$ & $\square$ & $\square$ & $\square$ & $\square$ & $\square$ \\
\hline \multirow{2}{*}{$\begin{array}{l}\text { OSW(11-20) } \\
\text { vs. sf36pcs }\end{array}$} & $\square$ OSW(11-20) & $\square$ sf36pcs $\geq 50)$ & $\square$ & $\square$ & $\square$ & $\square$ & $\square$ \\
\hline & $\square$ OSW $(11-20)$ & $\square$ sf36pcs $<50)$ & $\square$ & $\square$ & $\square$ & $\square$ & $\square$ \\
\hline \multirow{2}{*}{$\begin{array}{l}\text { OSW(21-30) } \\
\text { vs. sf36pcs }\end{array}$} & $\square$ OSW(21-30) & $\square \mathrm{sf} 36 \mathrm{pcs} \geq 50)$ & $\square$ & $\square$ & $\square$ & $\square$ & $\square$ \\
\hline & $\square$ OSW(21-30) & $\square$ sf36pcs $<50)$ & $\square$ & $\square$ & $\square$ & $\square$ & $\square$ \\
\hline \multirow{2}{*}{$\begin{array}{l}\text { OSW(31-40) } \\
\text { vs. sf36pcs }\end{array}$} & $\square$ OSW $(31-40)$ & $\square$ sf36pcs $\geq 50)$ & $\square$ & $\square$ & $\square$ & $\square$ & $\square$ \\
\hline & $\square$ OSW(31-40) & $\square$ sf36pcs $<50)$ & $\square$ & $\square$ & $\square$ & $\square$ & $\square$ \\
\hline \multirow{2}{*}{$\begin{array}{l}\text { OSW(41-50) } \\
\text { vs. sf36pcs }\end{array}$} & $\square$ OSW(41-50) & $\square \mathrm{sf36pcs} \geq 50)$ & $\square$ & $\square$ & $\square$ & $\square$ & $\square$ \\
\hline & $\square$ OSW(41-50) & $\square$ sf36pcs $<50)$ & $\square$ & $\square$ & $\square$ & $\square$ & $\square$ \\
\hline
\end{tabular}


Table 3.8: Questionnaire for OSW vs. BDI

\begin{tabular}{|c|c|c|c|c|c|c|c|}
\hline \multirow[t]{2}{*}{$\begin{array}{l}\text { Objective } \\
\text { Pairs }\end{array}$} & \multicolumn{2}{|c|}{ Pain outcome level } & \multirow{2}{*}{$\begin{array}{l}\text { If pain out- } \\
\text { come level } \\
\text { (a) and (b) } \\
\text { are equally } \\
\text { impor- } \\
\text { tant, then } \\
\text { check this } \\
\text { column. }\end{array}$} & \multicolumn{4}{|c|}{$\begin{array}{l}\text { If one is important than other one between (a) and (b), } \\
\text { then check the important one in pain outcome level col- } \\
\text { umn. After that check one of the columns from below } \\
\text { to show how important that checked pain outcome level } \\
\text { compare to other one. }\end{array}$} \\
\hline & (a) & (b) & & $\begin{array}{l}\text { Slightly } \\
\text { more im- } \\
\text { portant }\end{array}$ & $\begin{array}{l}\text { moderately } \\
\text { more impor- } \\
\text { tant }\end{array}$ & $\begin{array}{l}\text { strongly } \\
\text { more } \\
\text { important }\end{array}$ & $\begin{array}{l}\text { extremely } \\
\text { more } \\
\text { important }\end{array}$ \\
\hline \multirow{5}{*}{$\begin{array}{l}\text { OSW }(0-10) \\
\text { vs. BDI }\end{array}$} & $\square$ OSW $(0-10)$ & $\square \operatorname{BDI}(0-10)$ & $\square$ & $\square$ & $\square$ & $\square$ & $\bar{\square}$ \\
\hline & $\square$ OSW $(0-10)$ & $\square \operatorname{BDI}(11-14)$ & $\square$ & $\square$ & $\square$ & $\square$ & $\square$ \\
\hline & $\square$ OSW $(0-10)$ & $\square \operatorname{BDI}(15-18)$ & $\square$ & $\square$ & $\square$ & $\square$ & $\square$ \\
\hline & $\square$ OSW $(0-10)$ & $\square \operatorname{BDI}(19-30)$ & $\square$ & $\square$ & $\square$ & $\square$ & $\square$ \\
\hline & $\square$ OSW $(0-10)$ & $\square \mathrm{BDI}(31-63)$ & $\square$ & $\square$ & $\square$ & $\square$ & $\square$ \\
\hline \multirow{5}{*}{$\begin{array}{l}\text { OSW(11- } \\
20) \text { vs. } \\
\text { BDI }\end{array}$} & $\square$ OSW(11-20) & $\square \operatorname{BDI}(0-10)$ & $\square$ & $\square$ & $\square$ & $\square$ & $\square$ \\
\hline & $\square$ OSW $(11-20)$ & $\square \operatorname{BDI}(11-14)$ & $\square$ & $\square$ & $\square$ & $\square$ & $\square$ \\
\hline & $\square$ OSW $(11-20)$ & $\square \operatorname{BDI}(15-18)$ & $\square$ & $\square$ & $\square$ & $\square$ & $\square$ \\
\hline & $\square$ OSW $(11-20)$ & $\square \operatorname{BDI}(19-30)$ & $\square$ & $\square$ & $\square$ & $\square$ & $\square$ \\
\hline & $\square$ OSW $(11-20)$ & $\square \operatorname{BDI}(31-63)$ & $\square$ & $\square$ & $\square$ & $\square$ & $\square$ \\
\hline \multirow{5}{*}{$\begin{array}{l}\text { OSW(21- } \\
30) \text { vs. } \\
\text { BDI }\end{array}$} & $\square$ OSW(21-30) & $\square \operatorname{BDI}(0-10)$ & $\square$ & $\square$ & $\square$ & $\square$ & $\square$ \\
\hline & $\square$ OSW $(21-30)$ & $\square \operatorname{BDI}(11-14)$ & $\square$ & $\square$ & $\square$ & $\square$ & $\square$ \\
\hline & $\square$ OSW $(21-30)$ & $\square \operatorname{BDI}(15-18)$ & $\square$ & $\square$ & $\square$ & $\square$ & $\square$ \\
\hline & $\square$ OSW $(21-30)$ & $\square$ BDI(19-30) & $\square$ & $\square$ & $\square$ & $\square$ & $\square$ \\
\hline & $\square$ OSW $(21-30)$ & $\square \mathrm{BDI}(31-63)$ & $\square$ & $\square$ & $\square$ & $\square$ & $\square$ \\
\hline \multirow{5}{*}{$\begin{array}{l}\text { OSW(31- } \\
40) \text { vs. } \\
\text { BDI }\end{array}$} & $\square$ OSW $(31-40)$ & $\square \operatorname{BDI}(0-10)$ & 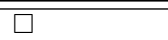 & $\bar{\square}$ & $\bar{\square} \square$ & $\bar{\square} \square$ & 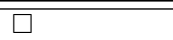 \\
\hline & $\square$ OSW $(31-40)$ & $\square \operatorname{BDI}(11-14)$ & $\square$ & $\square$ & $\square$ & $\square$ & $\square$ \\
\hline & $\square$ OSW(31-40) & $\square \operatorname{BDI}(15-18)$ & $\square$ & $\square$ & $\square$ & $\square$ & $\square$ \\
\hline & $\square$ OSW $(31-40)$ & $\square$ BDI(19-30) & $\square$ & $\square$ & $\square$ & $\square$ & $\square$ \\
\hline & $\square$ OSW $(31-40)$ & $\square \mathrm{BDI}(31-63)$ & $\square$ & $\square$ & $\square$ & $\square$ & $\square$ \\
\hline \multirow{5}{*}{$\begin{array}{l}\text { OSW(41- } \\
50) \text { vs. } \\
\text { BDI }\end{array}$} & $\square$ OSW(41-50) & $\square \operatorname{BDI}(0-10)$ & $\square$ & $\square$ & $\square$ & $\square$ & $\square$ \\
\hline & $\square$ OSW(41-50) & $\square \operatorname{BDI}(11-14)$ & $\square$ & $\square$ & $\square$ & $\square$ & $\square$ \\
\hline & $\square$ OSW(41-50) & $\square \operatorname{BDI}(15-18)$ & $\square$ & $\square$ & $\square$ & $\square$ & $\square$ \\
\hline & $\square$ OSW $(41-50)$ & $\square$ BDI(19-30) & $\square$ & $\square$ & $\square$ & $\square$ & $\square$ \\
\hline & $\square$ OSW $(41-50)$ & $\square$ BDI(31-63) & $\square$ & $\square$ & $\square$ & $\square$ & $\square$ \\
\hline
\end{tabular}

Table 3.9: Questionnaire for OSW vs. sf36mcs

\begin{tabular}{|c|c|c|c|c|c|c|c|}
\hline \multirow[t]{2}{*}{$\begin{array}{l}\text { Objective } \\
\text { Pairs }\end{array}$} & \multicolumn{2}{|c|}{ Pain outcome level } & \multirow{2}{*}{$\begin{array}{l}\text { If pain out- } \\
\text { come level } \\
\text { (a) and (b) } \\
\text { are equally } \\
\text { impor- } \\
\text { tant, then } \\
\text { check this } \\
\text { column. }\end{array}$} & \multicolumn{4}{|c|}{$\begin{array}{l}\text { If one is important than other one between (a) and (b), } \\
\text { then check the important one in pain outcome level col- } \\
\text { umn. After that check one of the columns from below } \\
\text { to show how important that checked pain outcome level } \\
\text { compare to other one. }\end{array}$} \\
\hline & (a) & (b) & & $\begin{array}{l}\text { Slightly } \\
\text { more im- } \\
\text { portant }\end{array}$ & $\begin{array}{l}\text { moderately } \\
\text { more impor- } \\
\text { tant }\end{array}$ & $\begin{array}{l}\text { strongly } \\
\text { more } \\
\text { important }\end{array}$ & $\begin{array}{l}\text { extremely } \\
\text { more } \\
\text { important }\end{array}$ \\
\hline \multirow{2}{*}{$\begin{array}{l}\text { OSW }(0-10) \text { vs. } \\
\text { sf36mcs }\end{array}$} & 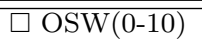 & $\overline{\square s f 36 m c s} \geq 50)$ & $\bar{\square} \square$ & $\overline{\square \square}$ & $\bar{\square}$ & $\bar{\square}$ & $\bar{\square}$ \\
\hline & $\square$ OSW $(0-10)$ & $\square$ sf36mcs $<50)$ & $\square$ & $\square$ & $\square$ & $\square$ & $\square$ \\
\hline \multirow{2}{*}{$\begin{array}{l}\text { OSW(11-20) } \\
\text { vs. sf36mcs }\end{array}$} & $\square$ OSW $(11-20)$ & $\square \mathrm{sf} 36 \mathrm{mcs} \geq 50)$ & $\square$ & $\square$ & $\square$ & $\square$ & $\square$ \\
\hline & $\square$ OSW $(11-20)$ & $\square \mathrm{sf} 36 \mathrm{mcs}<50)$ & $\square$ & $\square$ & $\square$ & $\square$ & $\square$ \\
\hline \multirow{2}{*}{$\begin{array}{l}\text { OSW }(21-30) \\
\text { vs. sf36mcs }\end{array}$} & $\square$ OSW(21-30) & $\square$ sf36mcs $\geq 50)$ & $\bar{\square} \square$ & 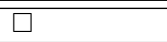 & $\square$ & 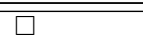 & $\square$ \\
\hline & $\square$ OSW $(21-30)$ & $\square$ sf36mcs $<50)$ & $\square$ & $\square$ & $\square$ & $\square$ & $\square$ \\
\hline \multirow{2}{*}{$\begin{array}{l}\text { OSW(31-40) } \\
\text { vs. sf36mcs }\end{array}$} & $\square$ OSW (31-40) & $\square \mathrm{sf} 36 \mathrm{mcs} \geq 50)$ & 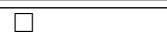 & $\bar{\square}$ & $\bar{\square}$ & $\square$ & $\bar{\square}$ \\
\hline & $\square$ OSW $(31-40)$ & $\square \mathrm{sf} 36 \mathrm{mcs}<50)$ & $\square$ & $\square$ & $\square$ & $\square$ & $\square$ \\
\hline \multirow{2}{*}{$\begin{array}{l}\text { OSW(41-50) } \\
\text { vs. sf36mcs }\end{array}$} & $\square$ OSW(41-50) & $\square \mathrm{sf} 36 \mathrm{mcs} \geq 50)$ & $\bar{\square} \square$ & $\bar{\square} \square$ & $\bar{\square} \square$ & 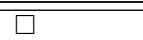 & 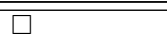 \\
\hline & $\square$ OSW $(41-50)$ & $\square \mathrm{sf} 36 \mathrm{mcs}<50)$ & $\square$ & $\square$ & $\square$ & $\square$ & $\square$ \\
\hline
\end{tabular}




\section{Chapter 4}

\section{Solution Approach}

This chapter details the computational results based on mathematical models discussed in chapter 3. Section 4.1 describes the description of data set, decision variables, and state variables. Analysis of weights from convex quadratic programming model as discussed in section 4.2. Section 4.3 shows the procedure to select an appropriate value for treatment cost coefficient, $\rho$. Section 4.4 describes the methods to choose appropriate sample size for this scenario based two-stage stochastic programming problem. Treatment analysis among this research, Wang [14], and observed data in both stages are shown in section 4.5. Final pain outcome comparisons among this research, observed data, and Wang [14] are shown in section 4.6. Finally, results from different types of additional 3 -way treatment interaction constraints are shown in section 4.7 .

\subsection{Case Study}

The data set used in this research was provided by the Eugene McDermott Center for pain management at UT Southwestern Medical Center. It has 294 observations, which means 294 patients completed both stage 1 and stage 2. Data was then divided into training and testing datasets consisting of 235 and 59 observations, respectively. The data set consists of 62 state variables, 5 mid-pain outcomes, 5 post-pain outcomes, 14 stage 1 decision variables, and 13 stage 2 decision variables. In stage 1 , there are 8 pharmaceutical treatment variables and 6 procedural treatment variables, while in stage 2 , there are 8 pharmaceutical variables and 5 procedural variables. Procedural variables are binary, while pharmaceutical variables are discrete level categorical. The description of the variables is shown in Table 3.1. We have used Pain Drawing Analogue (PDA), Oswestry Pain Disability Questionnaire (OSW), Beck Depression Inventory (BDI), Short Form 36 Physical Component Summary (sf36-pcs), and Short Form 36 Mental Health Component Summary (sf36-mcs) pain outcomes in this optimization model. Mid-PDA, mid-OSW, mid-BDI, mid-sf36pcs, and mid-sf36-pcs are used to measure the pain outcomes at the end of stage 1, and post-PDA, post-OSW, post-BDI, post-sf36-pcs, and post-sf36-pcs are used to measure the pain outcomes at the end of stage 2. We used a two-stage feature selection method to find optimal features [26]. These features fit a PLN model to the data, and remove useless inputs. We then ran the optimiza- 
tion problem to determine treatment policy, and compared the treatment policy with observed data and policies found in Wang [14]. A 6-minute time was used for the computational experiments.

\subsection{Weights from Convex Quadratic Programming}

To know the relationship between the multiple pain outcomes, we developed a survey for experts. The survey results are then put as parameters in a convex quadratic programming model that is described in section 3.2. After solving the convex quadratic model, we get the weights for OSW, PDA, BDI, SF36-pcs, and SF36-mcs. Figure 4.1 shows the weights for all five pain outcomes.

From Figures 4.1a-4.1c, we can see that higher pain outcomes have more penalty weights compare to lower scores for OSW, PDA, and BDI. As we already mentioned previously, if SF36 pain outcome scores are greater than 50, then it is in the normal level. Figures 4.1a and 4.1c show that sf36 pain outcomes have high penalty weights if their average score is less than 50, because the patients with an sf36 score of less than 50 need medication.

\subsection{Treatment Cost Coefficient}

We have used treatment cost coefficient parameter $(\rho)$ in the 2SP objective function 3.1a to make sure that cost function does not dominate pain outcomes. It is necessary to identify the appropriate value of $\rho$. We try with different $\rho$ values. We solve 2SP problems with a same sample size in both stages without any treatment interaction. Table 4.1 shows the treatment cost and average pain outcomes for different $\rho$ values.

Table 4.1: Determination of Treatment Coefficient

\begin{tabular}{c|c|c|c|c|}
\cline { 2 - 5 } & \multicolumn{4}{|c|}{ Treatment coefficient, $\rho$} \\
\cline { 2 - 5 } & 0.01 & 0.05 & 0.1 & 0.5 \\
\hline Treatment Cost & 184.11 & 147.01 & 131.19 & 82.02 \\
Avg. PDA & 4.99 & 5 & 5.02 & 5.06 \\
Avg. OSW & 8.14 & 8.73 & 9.49 & 11.58 \\
Avg. BDI & 3.19 & 3.56 & 3.81 & 5.1 \\
Avg. SF36pcs & 44.5 & 42.11 & 42.23 & 40.04 \\
Avg. SF36mcs & 50.35 & 50.27 & 50.2 & 49.79 \\
\hline
\end{tabular}

Treatment cost decreased with increasing value of $\rho$, while average pain outcome scores are increasing for PDA, OSW, BDI and decreasing for SF36pcs and SF36mcs (higher score of SF36 is better). Treatment cost is lowest for $\rho$ value of 0.5 , but for this value of $\rho$, we usually don't get any treatment for patients. This is because we are giving too much penalty on treatment. We choose 0.05 as a treatment cost coefficient. All the results below are based on $\rho=0.05$. 


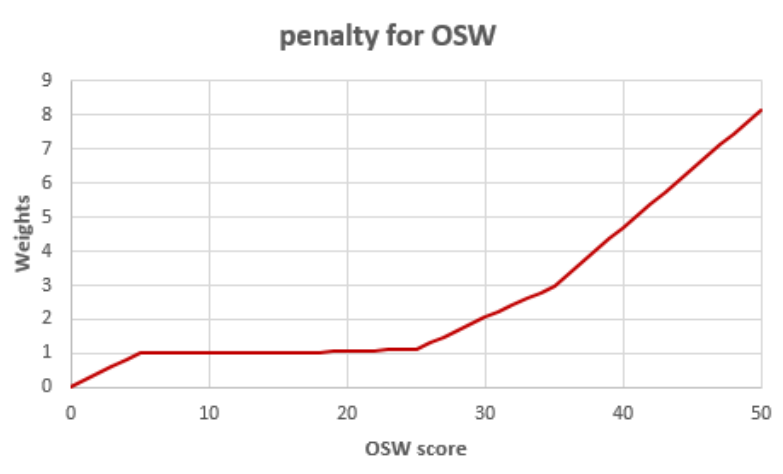

(a) Weights for OSW

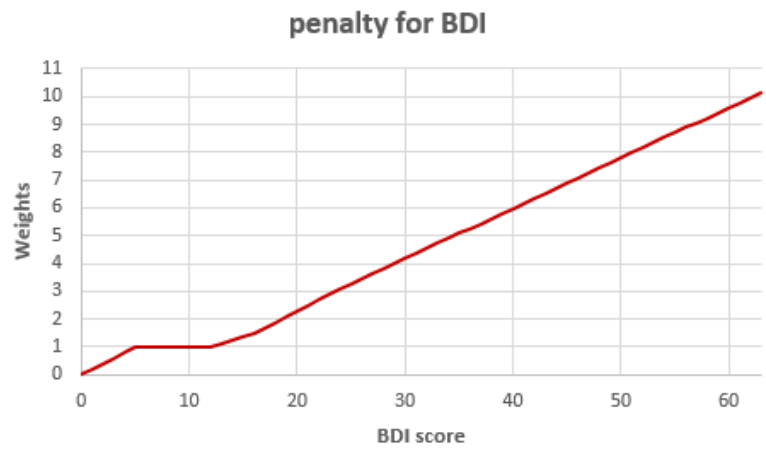

(c) Weights for BDI

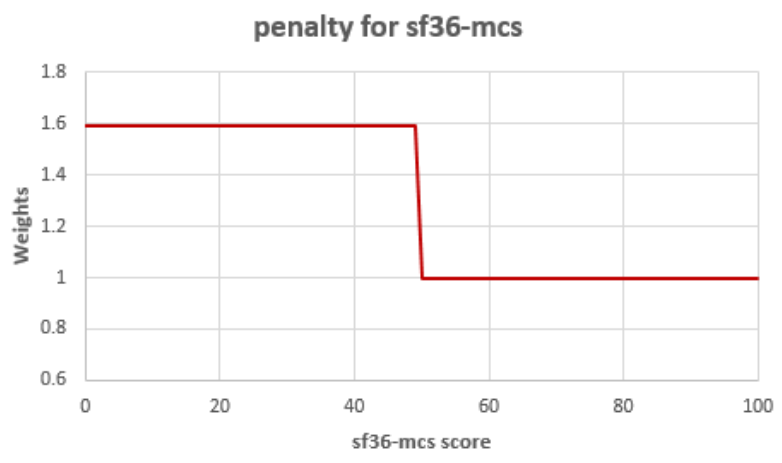

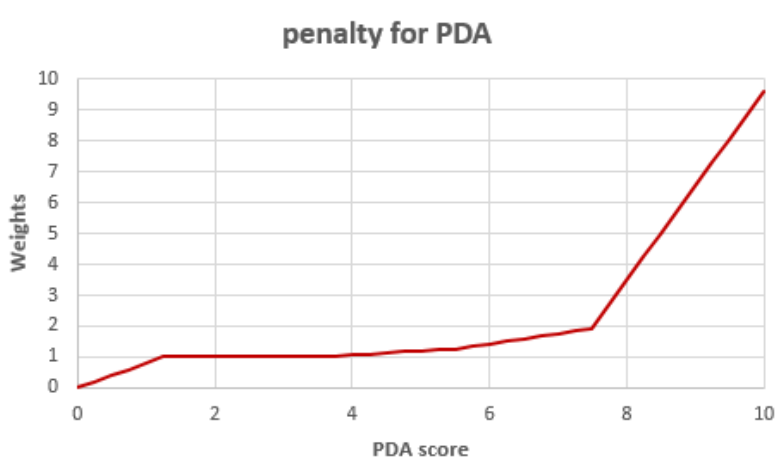

(b) Weights for PDA

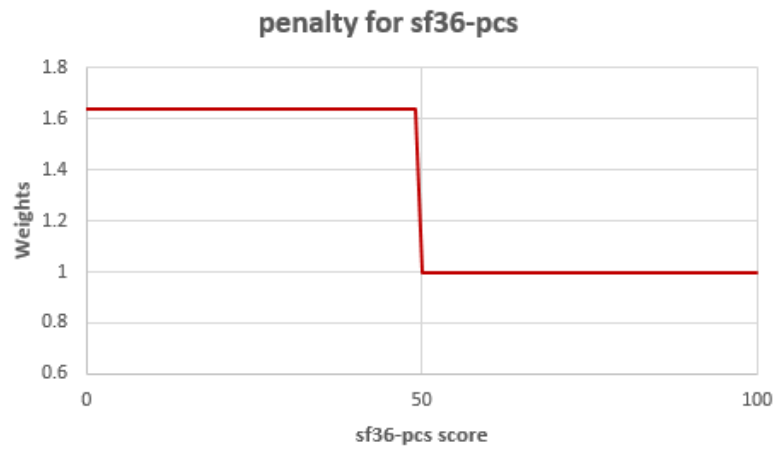

(d) Weights for SF36-pcs

(e) Weights for SF36-mcs

Figure 4.1: Penalty weights for OSW, PDA, BDI, SF36-pcs, and SF36-mcs

\subsection{Sample size determination}

In two-stage stochastic programming, discrete sampled scenarios are used to represent uncertainty, and it is important to identify an appropriate sample size. We ran the optimization software with sample sizes of $15,20,25$, and 30 for each stage. Average CPU times for policy generator, which is an equivalent deterministic model obtained bydiscretizing each random variable at each stage into $\mathrm{n}$ points, for different sample sizes for optimizing both the training and testing datasets are shown in figure 4.2. It is clear that CPU time increases along with increasing number of scenarios 


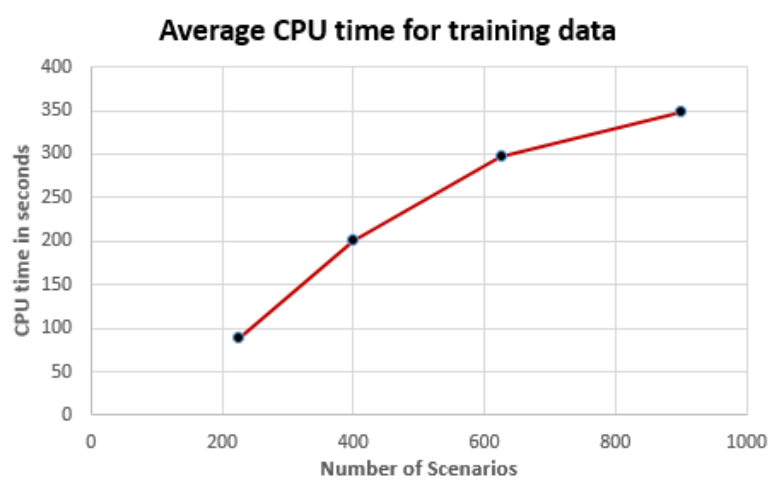

(a) CPU time for Training Dataset

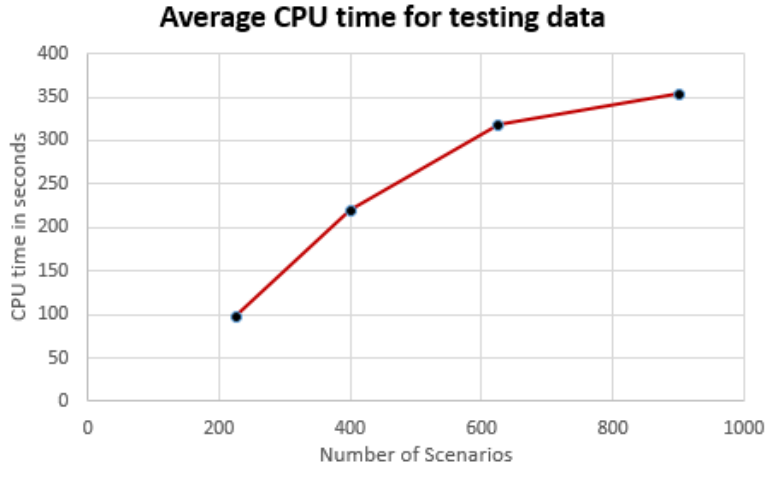

(b) CPU time for Testing Dataset

Figure 4.2: Average CPU time in different scenarios in Training and Testing data

$\left(\right.$ sample $\left.^{2}\right)$. For a small number of scenarios, CPU time is low. However, these small scenario sizes may not be able to represent the uncertainty in the two-stage stochastic programming model. We choose to use 625 scenarios (sample size of 25), because it takes an average of 300 seconds per patient to get the treatment policy, which is a reasonable waiting time.

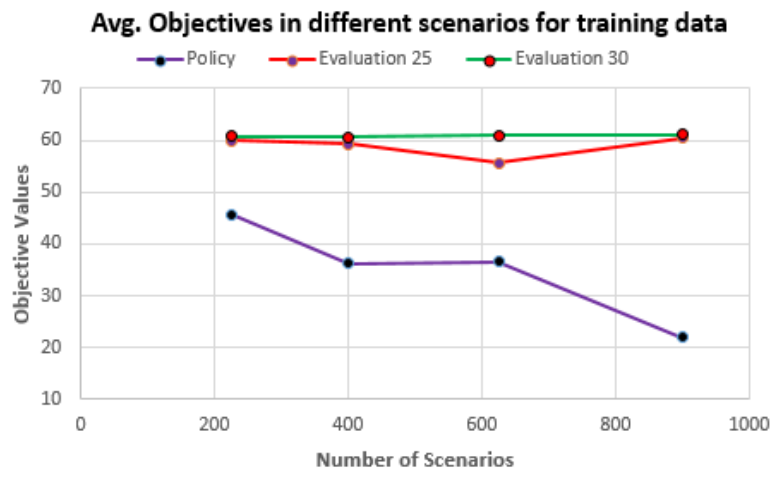

(a) Objective values for Training Dataset

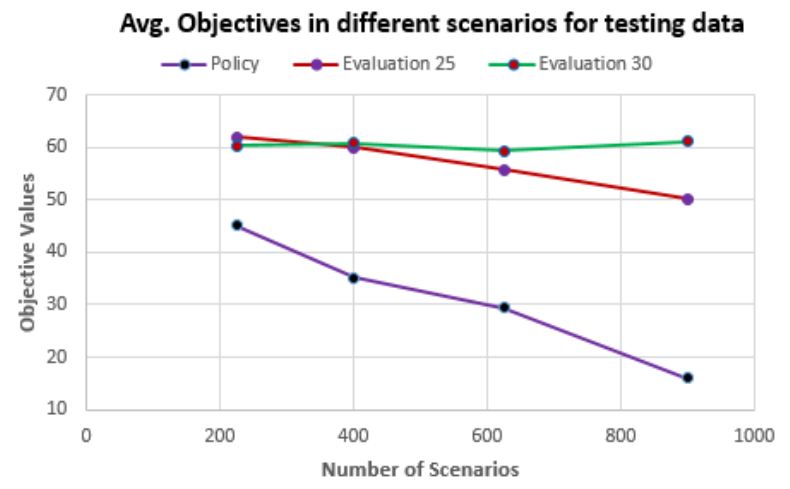

(b) Objective values for Testing Dataset

Figure 4.3: Average Objectives in different scenarios

Average objective values for both the training and testing dataset in case of policy generation is shown in figure 4.3 in the purple color line. The objective value is lower in for policy generation with 900 scenarios compared to other scenarios. However, as we have discussed before, using 900 scenarios takes an average of 360 seconds to give the treatment policy, and provably optimal solutions were not found for most of the patients. This is another reason for choosing 625 scenarios for policy generation. We then evaluated this policy using 625 and 900 scenarios. Evaluation is done using following mathematical equations to see the quality of the solution that is generated in policy generation stage. Let $x_{1(n)}^{*}$ be the optimal decision from policy generation model with sample size $n$. 


$$
\begin{aligned}
\min : & \sum_{i \in N} \sum_{j \in N_{i}} E\left(P_{u_{i j}}\left(\bar{Y}_{i 2}\left(\varepsilon_{1}, \varepsilon_{2}\right)\right)\right)+\rho\left(\sum C\left(x_{1}\right)+\sum E\left(C\left(x_{2}\left(\varepsilon_{1}\right)\right)\right)\right) \\
& \text { subject to: }(3.1 \mathrm{~b})-(3.1 \mathrm{f}), \&(3.2 \mathrm{~b})-(3.2 \mathrm{c}) \text { with sample size } m
\end{aligned}
$$

$$
x_{1}=x_{1(n)}^{*}
$$

The evaluated objective values are shown in red and green for 625 and 900 scenarios, respectively, in Figure 4.3. We choose 625 scenarios for evaluation because that gives the minimum objective values for 625 scenarios policy generation. Another reason is 625 scenarios for evaluation with 625 policy generations gives better pain outcomes, which is described in 4.6.

\subsection{Treatment Analysis}

This section compares treatment usage in different scenarios, and treatment usage frequency among this research, Wang [14], and observed data in both stages.
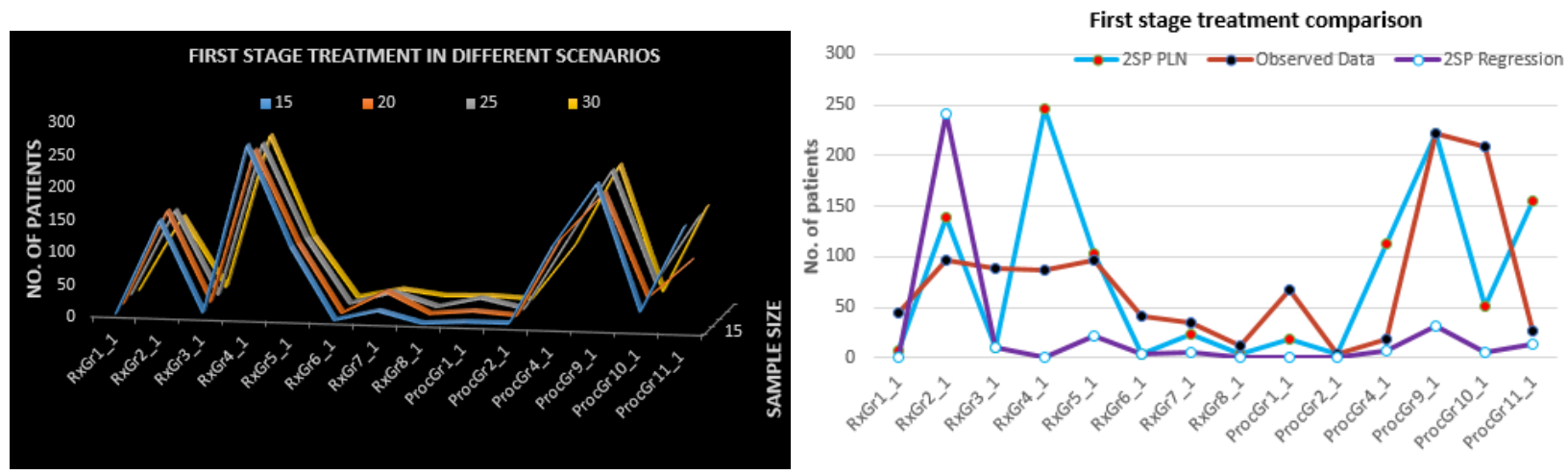

(a) First Stage Treatment usage with a different num- (b) First Stage Treatment Usage analysis in Observed ber of scenarios. dataset, Wang [14] (2SP Regression), and in this research (2SP PLN).

Figure 4.4: First Stage Treatment Analysis

\subsubsection{First Stage Treatment Usage in different Scenario}

Figure 4.4a shows the frequency of treatment usage in the first stage for a different sets of scenarios in this research. This figure demonstrates that Muscle Relaxant (RxGr4_1) is the most frequently used treatment, and Cognitive Behavior Therapy (ProcGr9_1) is the second most used treatment in almost all of the scenario sets in first stage. Tramadol (RxGr1_1), Narcotic (RxGr3_1), Tranquilizer (RxGr6_1), Sleeping Pills (RxGr7_1), Other Treatments (RxGr8_1), Injection (ProcGr1_1), and Block Procedures (ProcGr1_1) are applied to patients with low frequency $(<10 \%)$ in all the scenario sets. Since we have choose 625 scenarios (sample size 25) for policy generation, we will use the treatment policy for 625 scenarios for the remainder of this discussion. 


\subsubsection{First Stage Treatment Comparison}

Figure 4.4b shows first-stage treatment frequency in the observed data, in the 2SP regression from Wang [14], and 2SP PLN approach in this dissertation. It is clear that there is disagreement in the selected treatments across the 3 solutions. The most used treatment in stage 1 in the observed dataset is cognitive behavior therapy (ProcGr9_1), which is recommended to $76 \%$ of the patients. This treatment has been recommended in this research (2SP with PLN transition models) to $75 \%$ patients, which is pretty similar to observed data. However, the treatment policy from Wang [14] recommended this treatment to only $10 \%$ of the patients. Physical therapy (ProcGr10_1) is the second most used treatment in the observed data, while it was applied to $17 \%$ of the patients in this research, and only $2 \%$ of the patients in Wang [14]. One thing to notice is that the 2SP regression from Wang [14] seldom recommended procedural treatments, while the observed data and this research select most of the procedural treatments. The reason is that when a physician recommends treatment to patients, they consider all the aspects of pain. Even in this research we also considered 5 pain outcomes including Beck Depression Inventory, which is mostly treated with procedural treatments. As we mentioned earlier, Wang [14] considered only OSW as pain outcome, which is why procedural treatments were not recommended in her results.

In this research, the most used treatment is Muscle Relaxant (RxGr4_1). It is recommended to $30 \%$ of patients in the observed data, while it was never been recommended in Wang [14]. NSAID (RxGr2_1) is the only treatment that has been recommended to more than $30 \%$ of the patients in this research (48\%), 33\% in the observed data set, and $83 \%$ in Wang [14].

\subsubsection{Second Stage Treatment Usage in different Scenario}

Figure $4.5 \mathrm{a}$ shows the frequency of treatment usage in the second stage for different scenarios in this research. Similar types of treatment with slightly different frequency has been suggested in case of all scenario sets. Since we have choosen sample size 25 for policy generation, we will use the treatment profile of 625 scenarios to compare it with observed data and Wang [14].

\subsubsection{Second-Stage Treatment Comparison}

Treatment usage frequency of second stage in observed data, 2SP with regression from Wang [14], and in this research are shown in Figure 4.5b. In the observed dataset, we see all of the 13 treatments were recommended to patients. Block procedure (ProcGr2_2) was the least frequently used treatment in the observed dataset, but it was the most frequently used treatment (97\%) in this research. In Wang [14], Block Procedure was the most frequently used treatment as well. Cognitive behavior therapy (ProcGr9_2) treatment is most frequently used in the observed dataset, but it was recommended to only 1 patient both in this research and in Wang [14]. Physical therapy (ProcGr10_2) is the second most frequently recommended treatment in the observed dataset, while it is recommended as a treatment to only one patient in this research. However, it was never recommended in Wang [14]. Block Procedure (ProcGr2_2) is the most frequently used treatment 

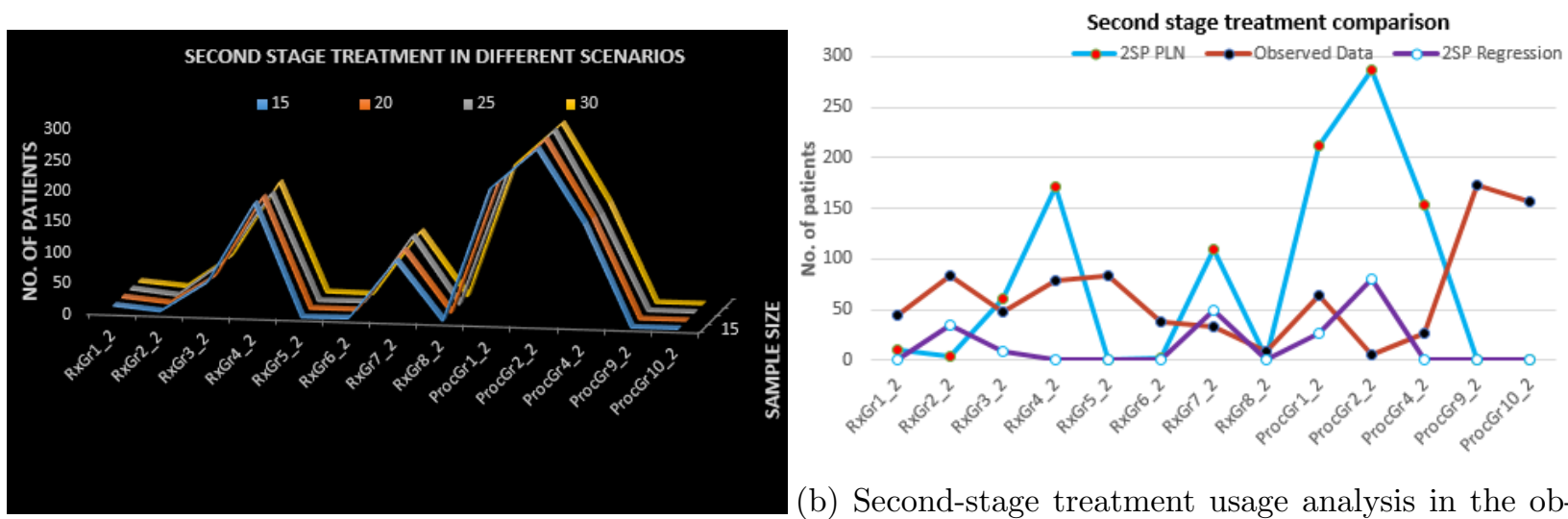

(a) Second Stage Treatment usage in different scenario

(b) Second-stage treatment usage analysis in the observed dataset, Wang [14] (2SP Regression), and in this research (2SP PLN)

Figure 4.5: Second Stage Treatment Analysis

both in this research (98\%) and in Wang (28\%) [14], while it was recommended to only $3 \%$ of the patients in the observed data. Sleeping pills $(\operatorname{RxGr7} 22)$ is the only treatment that was used to more than $10 \%$ of the patients in the observed data, in this research and in Wang [14].

\subsection{Final Pain Outcome Comparison}

We conduct odds ratio analysis to compare the performance of the optimization model with the observed data. Let, $S 1_{i}$ be the set of patients from observed data that required treatment after preevaluation for each pain outcome $i \in N$. Let $S 2_{i}$ and $S 3_{i}$ be the set of patients that achieve normal levels after post-evaluation for each pain outcome $i \in N$ in the observed data and optimization, where $\left(S 2_{i}, S 3_{i}\right) \in S 1_{i}$. The odds of the observed data, $O 1_{i}$, for each pain outcome $i \in N$ is calculated using $O 1_{i}=\left(\frac{\left|S 2_{i}\right|}{\left|S 1_{i}\right|-\left|S 2_{i}\right|}\right)$, and odds of optimization, $O 2_{i}$, for each pain outcome $i \in N$ is calculated using $O 2_{i}=\left(\frac{\left|S 3_{i}\right|}{\left|S 1_{i}\right|-\left|S 3_{i}\right|}\right)$. The odds ratio is the ratio of two odds. Since we want to see how the optimization model performs over the observed data for each pain outcome $i \in N$, we use $O R_{i}=\left(\frac{O 2_{i}}{O 1_{i}}\right)$ formula to calculate odds ratio.

Table 4.2 shows the number of patients requiring treatment in the beginning of the two-stage pain management program, and the number of patients that achieve normal pain level at the end of program for all five pain outcomes. In Figure 1.3, we showed the breakpoint of different levels of different pain outcomes. In this research, we consider the normal level of pain outcomes for PDA, OSW, and BDI are less than 6, less than 12, and less than 13 respectively; a mean score greater than 40 for SF36 is considered normal. If patients' pain outcomes are in these within these ranges, then they are assumed to be normal patients with limited pain [27]. From the observed data, we see that $84,38,149,30$, and 77 patients are in normal levels in the beginning of pain management program for PDA, OSW, BDI, SF36-pcs, and SF36-mcs pain outcomes respectively. We then find the final pain outcomes for the rest of the patients in the observed data and optimization results. 
Table 4.2: Pain Outcome Comparison

\begin{tabular}{|c|c|c|c|c|c|}
\hline & & & $\begin{array}{l}\text { No. of Patients } \\
\text { Required trt. }\end{array}$ & $\begin{array}{l}\text { No. of Patients in normal } \\
\text { Pain level after trt. }\end{array}$ & $\begin{array}{l}\text { Odds } \\
\text { Ratio }\end{array}$ \\
\hline \multirow{3}{*}{ PDA } & \multirow{2}{*}{ Optimization } & PLN & 210 & 201 & 4.62 \\
\hline & & Regression & 210 & 198 & 3.4 \\
\hline & \multicolumn{2}{|c|}{ Observed data } & 210 & 174 & - \\
\hline \multirow{3}{*}{ OSW } & \multirow{2}{*}{ Optimization } & PLN & 256 & 112 & 2.84 \\
\hline & & Regression & 256 & 103 & 2.46 \\
\hline & \multicolumn{2}{|c|}{ Observed data } & 256 & 55 & - \\
\hline \multirow{3}{*}{ BDI } & \multirow{2}{*}{ Optimization } & PLN & 145 & 142 & 36.37 \\
\hline & & Regression & 145 & 139 & 17.79 \\
\hline & \multicolumn{2}{|c|}{ Observed data } & 145 & 82 & - \\
\hline \multirow{3}{*}{ SF36-pcs } & \multirow{2}{*}{ Optimization } & PLN & 264 & 48 & 0.74 \\
\hline & & Regression & 264 & 53 & 0.83 \\
\hline & \multicolumn{2}{|c|}{ Observed data } & 264 & 61 & - \\
\hline \multirow{3}{*}{ SF36-mcs } & \multirow{2}{*}{ Optimization } & PLN & 217 & 131 & 2.06 \\
\hline & & Regression & 217 & 122 & 1.74 \\
\hline & Observe & data & 217 & 92 & - \\
\hline
\end{tabular}

Table 4.2 shows that 2SP with PLN policy gives better results compared to the observed data set in case of PDA, OSW, BDI, and SF36-mcs, while the SF36-pcs pain outcome in observed data is better compared to the results of $2 \mathrm{SP}$ PLN. This research achieves 4.62, 2.84, 36.37, 0.74, and 2.06 times more likely normal pain level for all the pain outcomes compared to the observed data. We also evaluated Wang's [14] first-stage treatment policies in our evaluation model to see which treatment policy is better in terms of number of patients with normal pain outcomes after thre pain management program. From table 4.2, this research has higher odds ratios for PDA, OSW, BDI, and SF36-mcs than Wang [14]. However, Wang's [14] treatments better for SF36-pcs. However, the observed data outperforms both this research and [14] in SF36-pcs.

\subsection{Results from Additional 3-way Treatment Interaction Con- straints}

Table 4.3 and 4.4 shows prelimiary results from adding additional 3-way treatment interaction constraints for continuous and discrete treatments variables to the original $2 \mathrm{SP}$ problem.

Table 4.3: Three-way treatment interaction Results: Continuous

\begin{tabular}{l|c|c|c|c|c|}
\cline { 2 - 6 } & 2-way & 3way_type I & 3way_type II & 3way_type III & 3way_all types \\
\hline No. optimal* & 147 & 238 & 147 & 141 & 138 \\
\hline Avg. CPU time & 301.61 & 264.75 & 305.67 & 300.4 & 305.69 \\
\hline
\end{tabular}

Using 3-way Type I interaction constraints, discussed in 3.4.2, along with 2-way treatment interaction constraints results in finding optimal treatments for almost $80 \%$ of the patients, and 
the average CPU time in this case is 264.75 seconds. Other types of additional 3-way treatment constraints did not yield better solutions compared to using only two-way treatment interactions.

Table 4.4: Three-way treatment interaction Results: Integer

\begin{tabular}{l|c|c|c|c|c|}
\cline { 2 - 6 } & 2-way & 3way_type I & 3way_type II & 3way_type III & 3way_all types \\
\hline $\begin{array}{l}\text { No. of patients } \\
\text { get optimal solu- } \\
\text { tion* }\end{array}$ & 88 & 88 & 49 & 100 & 44 \\
\hline Avg. CPU time & 320.72 & 320.8 & 338.61 & 317.30 & 340.0 \\
\hline
\end{tabular}

Table 4.4 shows that 3 -way treatment constraints for discrete treatment variables do not give better solutions compared with those of the continuous treatment variables. 


\section{Chapter 5}

\section{Conclusion and Future Work}

Pain management is a major health problem for many people. In this research we developed a multi-objective two-stage stochastic programming model, where our objective was minimizing a combination of pain outcomes and treatment cost as well. We have considered five pain outcomes in our optimization. We developed a survey to find penalty weights from the pain management experts. To ensure that weights are consistent, we developed a convex quadratic programming model. State transition models are non-convex Piecewise Linear Network (PLN) models, which are used as constraints in optimization model. To integrate these PLN models into optimization, we developed a mixed integer linear program. To speed up the solution process, we developed additional constraints based upon 3-way treatment interactions. Finally, we solved that MILP with AMPL/CPLEX. We compared our results with [14], who used non-convex quadratic transition models, and with the observed data set.

In future, we will work on generating a survey of treatment preferences for the physicians. Because some physicians prefer some treatments. We want to include those treatment preferences in the optimization model.

\section{Acknowledgement}

This research is funded by National Science Foundation grant CMMI-1434401 


\section{Bibliography}

[1] K. McGann, Fundamental Aspects of Pain Assessment and Management. Quay Books division, 2007.

[2] J. H. Silverstein, C. H. McLeskey, J. Reves, and G. A. Rooke, Geriatric anesthesiology. Springer, 2008.

[3] E. Nolte, C. Knai, and M. McKee, Managing chronic conditions: experience in eight countries. WHO Regional Office Europe, 2008, no. 15.

[4] B. E. Gould and R. Dyer, Pathophysiology for the Health Professions-E-Book. Elsevier Health Sciences, 2010.

[5] M. A. Ashburn and P. S. Staats, "Management of chronic pain," The Lancet, vol. 353, no. 9167, pp. 1865-1869, 1999.

[6] P. Fine, "Difficulties and challenges in the treatment of chronic pain in the older adult," AMERICAN JOURNAL OF PAIN MANAGEMENT, vol. 14, no. 2; SUPP, pp. 2S-8S, 2004.

[7] S. J. Lipson, "Spinal-fusion surgery—advances and concerns," New England Journal of Medicine, vol. 350, no. 7, pp. 643-644, 2004.

[8] F. I. F. on Aging-Related Statistics, Older Americans 2008: Key indicators of well-being. Government Printing Office, 2008.

[9] C. for Disease Control and Prevention, "National center for health statistics," http://www.cdc.gov/nchs/fastats/inpatient-surgery.htm/, 2010, [Online; accessed 10-July2016]. 
[10] G. Aston, "Hospitals \& health networks," http://www.hhnmag.com/articles/3989-awarenessof-patient-safety-grows-with-increased-outpatient-surgeries/, 2014, [Online; accessed 10-July2016].

[11] E. Chevlen, "Optimizing the use of opioids in the elderly population," AMERICAN JOURNAL OF PAIN MANAGEMENT, vol. 14, no. 2; SUPP, pp. 19S-24S, 2004.

[12] C. F. Lin, "Adaptive pain management decision support system," Ph.D. dissertation, Faculty of the Graduate School, University of Texas at Arlington, December 2010.

[13] E. M. Tourist, "European Medical Tourist Oswestry Disability Index," http://www.europeanmedicaltourist.com/88/, 2016, [Online; accessed 16-February-2016].

[14] N. Wang, "Two-stage stochastic programming for adaptive interdisciplinary pain management," Ph.D. dissertation, Faculty of the Graduate School, University of Texas at Arlington, May 2015.

[15] A. K. Leboulluec, "Outcome and state transition modeling for adaptive interdisciplinary pain management," Ph.D. dissertation, Faculty of the Graduate School, University of Texas at Arlington, December 2013.

[16] W. Gu, X. Wang, and S. E. McGregor, "Optimization of preventive health care facility locations," International Journal of Health Geographics, vol. 9, no. 1, p. 17, 2010.

[17] M. A. Ahmed and T. M. Alkhamis, "Simulation optimization for an emergency department healthcare unit in kuwait," European Journal of Operational Research, vol. 198, no. 3, pp. 936-942, 2009.

[18] F. F. Baesler and J. A. Sepúlveda, "Multi-objective simulation optimization for a cancer treatment center," in Simulation Conference, 2001. Proceedings of the Winter, vol. 2. IEEE, 2001, pp. 1405-1411.

[19] S. L. Rosen, C. M. Harmonosky, and M. T. Traband, "A simulation optimization method that considers uncertainty and multiple performance measures," European Journal of Operational Research, vol. 181, no. 1, pp. 315-330, 2007. 
[20] Y. Huang, H. Zheng, C. Nugent, P. McCullagh, N. Black, K. E. Vowles, and L. McCracken, "Feature selection and classification in supporting report-based self-management for people with chronic pain," IEEE Transactions on Information Technology in Biomedicine, vol. 15, no. 1 , pp. 54-61, 2011.

[21] S. Ali, P. Chia, and K. Ong, "Graphical knowledge-based protocols for chest pain management," in Computers in Cardiology, 1999. IEEE, 1999, pp. 309-312.

[22] L. Goldman, E. F. Cook, D. A. Brand, T. H. Lee, G. W. Rouan, M. C. Weisberg, D. Acampora, C. Stasiulewicz, J. Walshon, G. Terranova et al., "A computer protocol to predict myocardial infarction in emergency department patients with chest pain," New England Journal of Medicine, vol. 318, no. 13, pp. 797-803, 1988.

[23] H. Chandrasekaran, J. Li, W. H. Delashmit, P. L. Narasimha, C. Yu, and M. T. Manry, "Convergent design of piecewise linear neural networks," Neurocomputing, vol. 70, no. 4, pp. 1022-1039, 2007.

[24] K. A. Matthews, S. L. Crawford, C. U. Chae, S. A. Everson-Rose, M. F. Sowers, B. Sternfeld, and K. Sutton-Tyrrell, "Are changes in cardiovascular disease risk factors in midlife women due to chronological aging or to the menopausal transition?" Journal of the American College of Cardiology, vol. 54, no. 25, pp. 2366-2373, 2009.

[25] P. S. Reynolds and G. S. Chiu, "Understanding thermoregulatory transitions during haemorrhage by piecewise regression," arXiv preprint arXiv:1006.5117, 2010.

[26] R. Rawat and M. T. Manry, "Second order training of a smoothed piecewise linear network," Neural Processing Letters, pp. 1-28, 2017.

[27] R. J. Gatchel, Clinical essentials of pain management. American Psychological Association, 2005. 